\title{
IMPROVING THE LIVELIHOODS OF WOMEN IN \\ THE DEVELOPING WORLD: SELECTED \\ PERCEPTIONS OF WOMEN'S \\ SELF-HELP GROUPS IN \\ WESTERN KENYA
}

\author{
By \\ BILLYSTROM ARONYA JIVETTI \\ Bachelor of Science in Biology \\ Kenyatta University \\ Nairobi, Kenya \\ October 1999
}

Master of Environmental Science

Miami University

Oxford, Ohio

December 2004

Submitted to the Faculty of the

Graduate College of the

Oklahoma State University

in partial fulfillment of

the requirements for

the Degree of

MASTER OF SCIENCE

December 2007 


\section{IMPROVING THE LIVELIHOODS OF WOMEN IN \\ THE DEVELOPING WORLD: SELECTED \\ PERCEPTIONS OF WOMEN'S \\ SELF-HELP GROUPS IN WESTERN KENYA}

Thesis Approved:

\begin{tabular}{c} 
Dr. Craig Edwards \\
\hline Thesis Adviser \\
Dr. Jerry Jordan \\
\hline Dr. Cindy Blackwell \\
\hline Dr. A. Gordon Emslie
\end{tabular}




\section{DEDICATION}

Around 1972, my mother, Mrs. Rose Jiveti helped initiate the Kakamega Women's Cottage Industry (KWCI) as a grassroots society to assist and empower local women from Kaimosi area, of Western Kenya, through informal self-employment and entrepreneurial activities. That organization grew to become one of the most illustrious in that part of the country. Most of the women who were members of the group held me when I was born, and nicknamed me "Peter", after a German volunteer who was working with them. As a family, we were able to afford our basics in life such as attending school, based on, partly, what my mother got from the sale of tie and dye, pottery, and basketry products. I am who I am now, because of the gift of my mother, through collective action with other local women, which allowed me to pursue an education, during those humble times. I know many more sons and daughters in our community who were never fortunate enough to get such an opportunity. That spirit of collective action by those dear women, then members of Kakamega Cottage Industry, inspired me to undertake this study. 


\section{ACKNOWLEDGEMENTS}

I am exceptionally grateful to Dr. Jim Hromas, Director, School of International Studies and International Education and Outreach, for the grand support inform of assistantships, research and conference funds. Special mention also goes to Dr. Cornel Thomas, VP Institutional Diversity, for his support towards funding my education at OSU.

I made many generous friends at OSU whom I will cherish forever. My village mate Mr. Patrick Saisi was so instrumental throughout my sojourn at OSU. We shared and encouraged ourselves many times when we were up or down, high or low, angry or happy. Dr. David Njite stood with me in many special moments, thank you. Dr. Mwarumba Mwavita richly encouraged me throughout the life of this project.

Dr. Michael Craig Edwards, my thesis committee chair and advisor greatly nurtured me in this process of academic writing and refined my work, into the 'precious stone' it is. We spent many hours working on this project, many of them sacrificial. Forever, I will remain indebted to him. My other committee members Dr. Jerry Jordan and Dr. Cindy Blackwell were wonderful and awesome people whom I enjoyed working with. Thank you for your support.

I pay glowing tribute to Mr. Hardly Songole Sinjaa and Mrs Lydia Sinjaa, my research assistants who devoted their best resource - time, on this project. It is embedded in my heart. Ms. Christabel Khadioli's role remains unforgettable. 
To all the women who belonged to the self-help groups that readily provided information for this study, murhio muno! I am on a journey whose fruits, I am optimistic, will bring me back home, to you.

Above all, Lillian and Belinda withstood my long periods of absence while working on this project. Thank you, my dear wife and daughter for the support extraordinaire.

Thanks to God for granting me a healthy stay at OSU. 


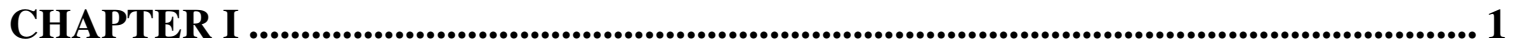

1.0.0 INTRODUCTION.............................................................................................................. 1

1.1.0 Rationale for the Study ........................................................................ 2

1.2.0 Problem Statement .................................................................................... 4

1.3.0 What has changed since the 1980s in Kenya? .................................................. 7

1.4.0 Increasing Importance of Self-Help Groups .................................................... 9

1.5.0 Changing Educational and Training Needs ………................................... 9

1.6.0 Purpose of the Study ................................................................................. 10

1.7.0 Research Questions .................................................................................. 10

1.8.0 Profile and Description of Study Area......................................................... 11

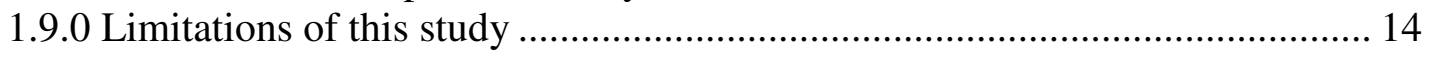

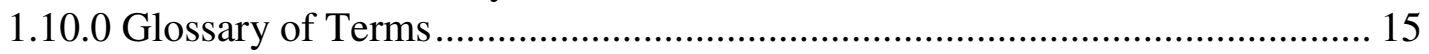

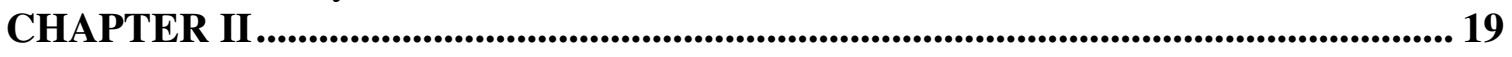

REVIEW OF LITERATURE ................................................................................................. 19

2.0.0 Summary ………................................................................................ 19

2.1.0 General Aspects of Poverty in the Developing World.................................... 21

2.2.0 Feminization of Poverty.............................................................................. 24

2.3.0 Women's "Self-Help" Groups and Associations .............................................. 27

2.4.0 Rural Women in Kenya ........................................................................... 30

2.5.0 The Concept of Women's Groups in Kenya................................................... 31

2.6.0 Objectives of Today's Women's Groups........................................................ 32

2.7.0 Women's Work in Agriculture in Kenya ........................................................... 34

2.8.0 Importance of Women's Self-Help Groups to Their Communities.................. 35

2.9.0 Obstacles facing Women's Groups in Kenya ................................................. 37

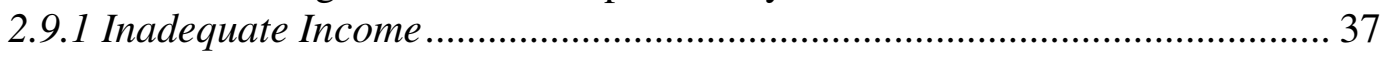

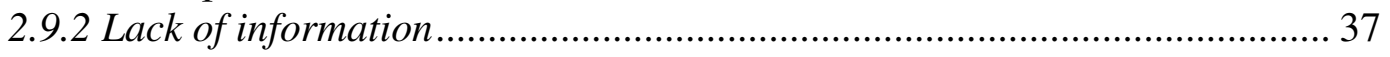

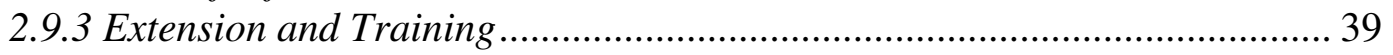

2.9.4 Sales, Marketing, and Management Problems ......................................... 40

2.9.5 Inadequate Business and Vocational Training .......................................... 41

2.9.6 Education and Training: What is Needed.................................................... 42

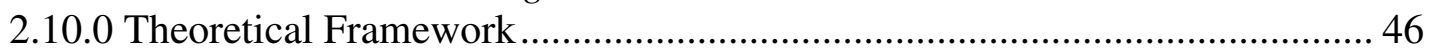

CHAPTER III .................................................................................................................................. 50

METHODOLOGY …….................................................................................................... 50

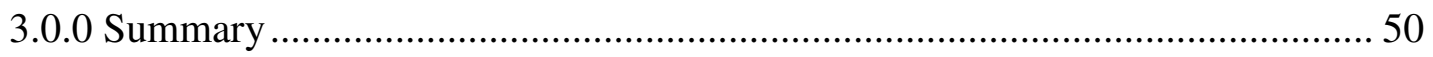

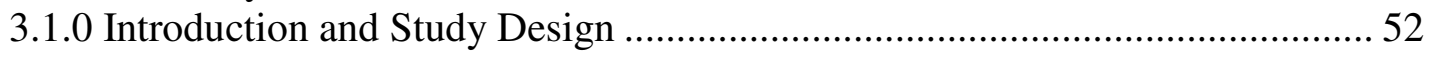

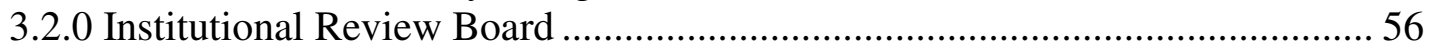




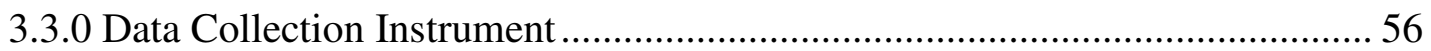

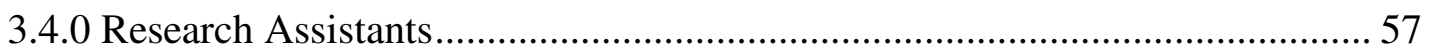

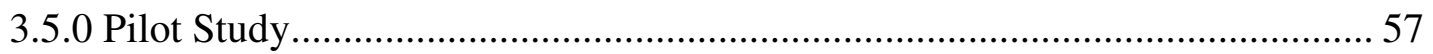

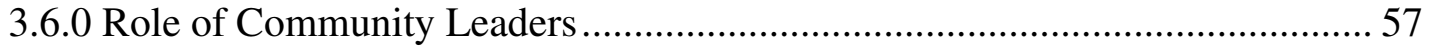

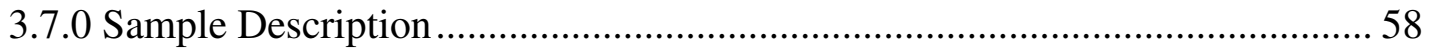

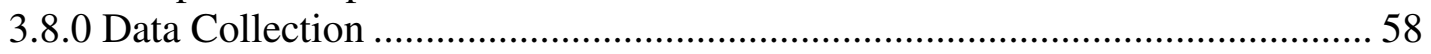

3.9.0 Languages Used During the Interviews ...................................................... 59

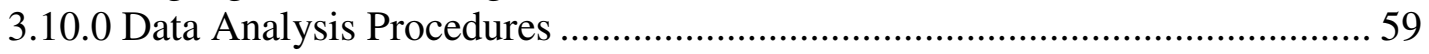

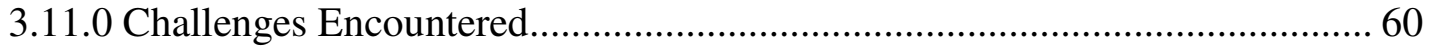

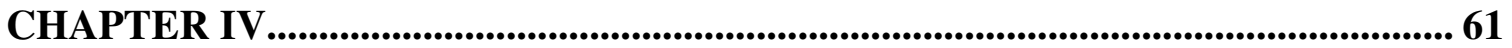

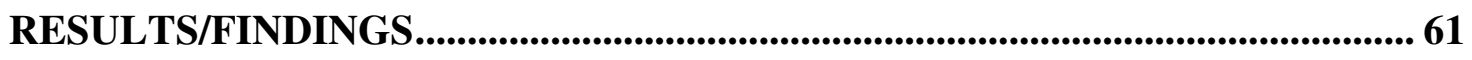

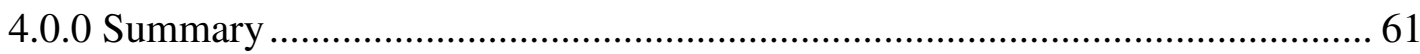

4.1.0 Selected Characteristics of the Women's Self-Help Groups and Their Members in the Shaviringa Location, Vihiga District of Western Kenya ............................... 63 4.2.0 Selected Perceptions of Women about the Formation, Primary Activities, and Benefits of Their Self-Help Groups in the Shaviringa Location, Vihiga District of Western Kenya........................................................................................... 66 4.3.0 Selected Perceptions of Women Regarding Their Needs for Education and Training as it Pertained to the Acquisition of Vocational and Business Skills by Members of Their Self-Help Groups in the Shaviringa Location, Vihiga District of Western Kenya. 4.4.0 Selected Perceptions of Women Regarding Access to Information and Use of Communication Channels by Members of Their Self-Help Groups in the Shaviringa Location, Vihiga District of Western Kenya ..... 72 4.5.0 Selected Perceptions of Women Concerning the Governance, Management, and Leadership of Their Self-Help Groups in the Shaviringa Location, Vihiga District of Western Kenya 74 4.6.0 Selected Perceptions of Women Regarding the Financial Operations of Their Self-Help Groups in the Shaviringa Location, Vihiga District of Western Kenya... 76 4.7.0 Selected Perceptions of Women Regarding Other Factors That Affected the Performance of Their Self-Help Groups in the Shaviringa Location, Vihiga District

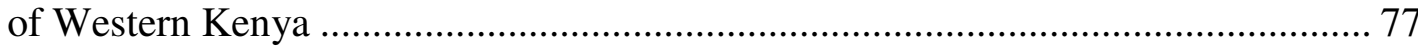

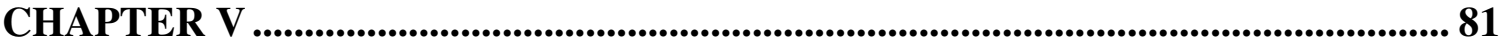

SUMMARY AND CONCLUSIONS ..................................................................... 81

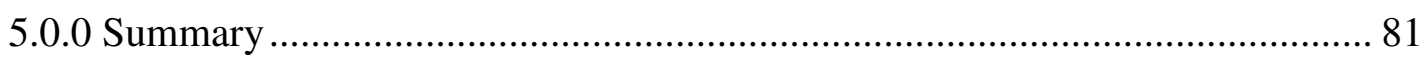

5.1.0 Selected Characteristics of the Women's Self-Help Groups and Their Members in the Shaviringa Location, Vihiga District of Western Kenya .............................. 83 5.2.0 Selected Perceptions of Women about the Formation, Primary Activities, and Benefits of Their Self-Help Groups in the Shaviringa Location, Vihiga District of Western Kenya 84 
5.3.0 Selected Perceptions of Women Regarding Their Needs for Education and Training as it Pertained to the Acquisition of Vocational and Business Skills by Members of Their Self-Help Groups in the Shaviringa Location, Vihiga District of

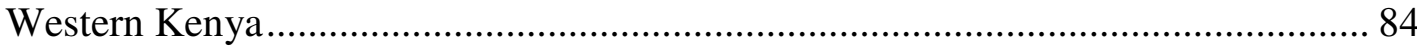

5.4.0 Selected Perceptions of Women Regarding Access to Information and Use of Communication Channels by Members of Their Self-Help Groups in the Shaviringa Location, Vihiga District of Western Kenya ..... 84

5.5.0 Selected Perceptions of Women Concerning the Governance, Management, and Leadership of Their Self-Help Groups in the Shaviringa Location, Vihiga District of Western Kenya ....

5.6.0 Selected Perceptions of Women Regarding the Financial Operations of Their Self-Help Groups in the Shaviringa Location, Vihiga District of Western Kenya... 85 5.7.0 Selected Perceptions of Women Regarding Other Factors That Affected the Performance of Their Self-Help Groups in the Shaviringa Location, Vihiga District

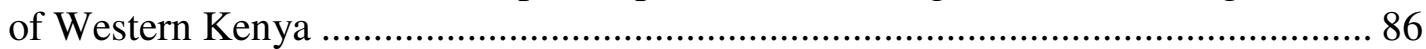

5.8.0 RECOMMENDATIONS.................................................................................... 87

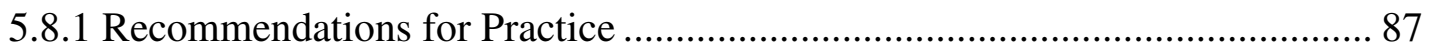

5.8.2 Recommendations for Future Research ................................................. 92

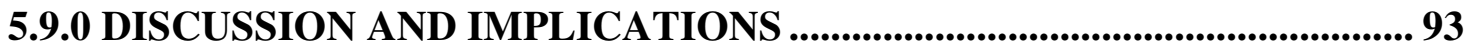

REFERENCES....................................................................................... 101

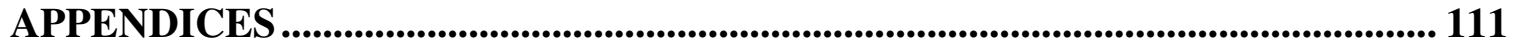

APPENDIX A

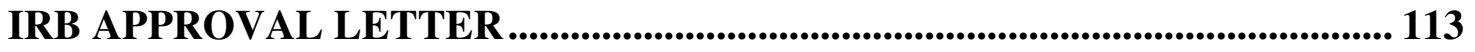

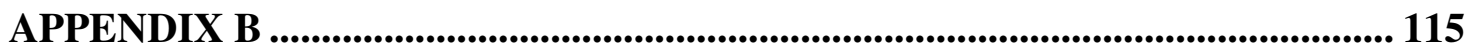

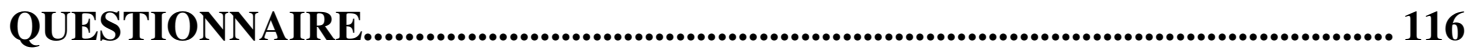




\section{LIST OF TABLES}

Table $\quad$ Page

1. 1999 and 2006 Projected Kenya National Census Statistics for Shaviringa Location, Tiriki East Division, Vihiga District of Western Kenya........................22

2. Selected Characteristics of Women's Self-Help Groups and Their Members in the Shaviringa Location, Vihiga District of Western Kenya......................... 74

3. Selected Perceptions of Women about the Formation, Primary Activities, and Benefits of Their Self-Help Groups in the Shaviringa Location, Vihiga District of Western Kenya...................................................... 77

4. Women's Self-Help Groups' Perceptions of Their Education and Training Needs in the Shaviringa Location, Vihiga District of Western Kenya........................81

5. Existing Sources of Information and Communication Channels as Expressed by Women's Self-Help Groups in the Shaviringa Location, Vihiga District of Western Kenya................................................................ 83

6. Factors Affecting Governance, Management and, Leadership of Women's Self-Help Groups in Shaviringa Location, Vihiga District of Western Kenya................84

7. Factors Influencing Financial Operations of Women's Self-Help Groups in the Shaviringa Location, Vihiga District of Western Kenya......................... 86

8. Other Factors Affecting Women's Self-Help Groups Regarding Their General Performance in the Shaviringa Location, Vihiga District of Western Kenya.... 


\section{LIST OF FIGURES}

Figure

Page

1. Map of Kenya showing Vihiga District and project

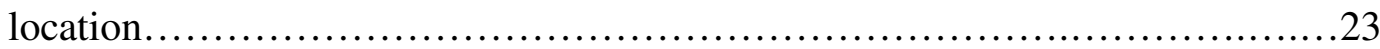

2. Age categories of members of women's self-help groups in the Shaviringa

Location, Vihiga District of Western Kenya.................................75 


\section{CHAPTER I}

\subsubsection{INTRODUCTION}

The poorest of the world's poor are women who comprise over two-thirds of the people living on less than one USD per day (United Nations, 2001). The poor's privations transcend their need for micro-credit; they also lack entrepreneurial skills (Snow \& Buss, 2001). Because women are major economic actors, heads of households, and mothers, their poverty slows growth and results in spirals of poverty, population growth, and environmental degradation (Buvinic, 1997). Buvinic's study of poverty in 41 developing countries revealed that more women in rural communities were poor. They shoulder economic burdens as farmers, abandoned wives, young widows, and young mothers. However, huge opportunities for their employment in Sub-Saharan Africa occur in "the small-scale[,] informal sector enterprises" (Ziderman, 2003, p. 1).

Lack of proper training and skills further exacerbates women's poverty causing a vicious cycle of impoverishment from one generation to the next. The result is a growing global trend of poverty that Buvinic (1997) posited was the "feminization of poverty." The development of skills through targeted programs is vital for disadvantaged groups, e.g., the poor, minorities, and women; this could better enable them to function well in the informal sector (Ziderman, 2003). In some cases, women are showing competence already through the use of "informal networks" popularly known as "women's self-help 
groups." The actions of these groups also complement other efforts to reduce poverty (Snow \& Buss, 2001) and improve rural lives. These associations are used as means to successfully adapt to the external challenges found in many of today's societies (Kiteme, 1992; Mbugua-Murithi, 1997). So, many aid agencies are now embracing such "informal institutions" because of their role in economic development and as a complement to "bottom-up" community development approaches which may mitigate government failures (Snow \& Buss, 2001). As Snow and Buss observed, proper "bottom-up" practices call for an improvement in human capabilities such as the need for education and improved business infrastructure. Recently, the focus of women's groups in Kenya has been on educational and economic issues that were prompted partly by Structural Adjustment Programs (SAPs) promulgated by The World Bank and the International Monetary Fund (IMF) (Mbugua-Murithi, 1997). Accordingly, research on the education of women finds a potential synergy that includes both economic and human development (Mbugua-Murithi).

\subsubsection{Rationale for the Study}

1. Rural African women through interaction with their social and natural environment play a significant role in the fight against poverty. This is a study whose research findings could inspire policy change and interventions to mitigate the phenomenon called feminization of poverty (Buvinic, 1997). 
2. The escalating poverty among women in the rural areas of Africa calls for intensified, innovative, multi-disciplinary, and culturally relevant research that responds to rural African women's needs, challenges, priorities, and realities (Mbugua-Murithi, 1997).

3. The need and demand for education and information about "bottom-up" development strategies by businesses, governments and other development agencies exists.

Research on rural projects could provide an excellent bottom-up development model to be incorporated into local, national, and international policies aimed at changing the economic status of women (Kiteme, 1992).

4. Kenya, similar to most African countries, is culturally diverse (Udvardy, 1998). This study is sited in a region in Kenya that includes one of the largest tribes that is culturally diverse - Luhya tribe. It is important to appreciate the role of cultural and ethnic differences when designing programs and policies for women (Shibanda \& Seru, 2002).

5. The roles of rural women in food production, household duties, non-farm chores, and other socioeconomic aspects are enormous (Buvinic 1997). Vihiga District is one of the poorest Districts in Kenya (Waithaka, Thornton, Herrero, \& Shepherd, 2006). Significant development research is yet to be undertaken to understand, quantify, or describe this phenomenon. Such data is needed to be effectively incorporated with emerging technologies and new social empowerment strategies, including workforce and business training and education to help women. 


\subsubsection{Problem Statement}

According to the 1999 national census, Kenya's population was estimated at 30.1 million (Freeman, Ellis, \& Allison, 2004) of which 68\% live in rural areas with a poverty rate of 46.4\% (Ashley \& Maxwell, 2001). As a consequence, about 50\% of Kenyans live below the poverty level, mainly, in the rural areas where the major challenge is to increase agricultural production because it is their mainstay. Increasing rural agricultural production would help curb rural-urban migration and create job opportunities for the rural population (Kiteme, 1992).

Structural adjustment programs by the International Monetary Fund and the World Bank have shifted responsibility from the government to the households (MbuguaMurithi, 1997). This has also contributed significantly to the decrease of formal employment opportunities and working capital in rural areas, although the informal sector has been absorbing many jobs (Neitzert, 1996; Snow \& Buss, 2001).

Male exodus and continued absence from rural areas causes a drain on the rural labor force, thus leaving women as de facto leaders and providers for their households (Kiteme, 1992). As household heads, this position is disadvantageous economically, socially, legally, and culturally. Because of these disadvantages, women are forced to design strategies to overcome problems (Mbugua-Murithi, 1997). The response by many women has been the formation of informal institutions, popularly known as “women's self-help groups" to complement their efforts toward alleviating poverty and mitigating educational and other socioeconomic needs (Lanier, 1968; Mbugua-Murithi, 1997; Snow \& Buss, 2001). 
Community groups are popular institutions in rural Kenyan communities because they help provide services that the public service has failed to address; they take the forms of women's groups, youth groups, burial groups, or church mission groups (Freeman, Ellis, \& Allison, 2004). Such organizations open new opportunities to generate, save, and invest income and assist women in effectively responding to dynamic socio-economic changes as individuals, family heads, or as a community (Kiteme 1992). Similarly, they could be powerful vehicles for the diversification of livelihoods in rural communities (Mwabu \& Thorbecke, 2004).

As the rural areas continue to grow in population, an increase in the demand for infrastructure and services exists such as water supply, education, health services, and the provision of vocational training programs (Anderson \& Leiserson, 1980; Karani, 1987; Thomas, 1988; Noordin, Niang, Jama, \& Nyasimi, 2001). Extension and development agencies are increasingly relying on women's groups as instruments to disseminate information about improved agriculture, livestock production, health, and new technologies in rural areas (Udvardy, 1998). Some of their activities include the provision of educational, health, water, agriculture, and other community services (Karani, 1987; Srujana, 1996; Thomas, 1987). Income-generating and welfare are their main objectives (Kamar, 1999; Karani, 1987; Karega, 1996). Implementing such development projects in their communities requires organizational and leadership skills in making decisions, income generation, and mobilization of community members (Feldman, 1983).

Therefore, it is important to examine the roles, functions, and other pertinent issues arising from the use of such local organizations to promote development (Thomas, 1987). For instance, women's groups have to contend with issues such as inadequate 
capital (Kamar 1999; Mwaniki, 1986; Srujana, 1996), lack of follow-up by extension staff (Kamar, 1999), the overall perceptions that women's projects are merely short term solutions to their idiosyncratic problems and not very important to national development (Mwaniki, 1986), or that women's groups are just welfare associations in spite of engaging in entrepreneurship through their income-generating activities (Karega, 1996), and inadequate access to information (Mutua-Kombo, 2001).

Despite playing such vital roles there is evidence that most training programs neglect women's groups (Feldman, 1983). Existing development programs and policies seem to undermine women's groups' roles and do not account for women's groups' specific local needs (Thomas, 1988). According to Kamar (1999), the success of women's groups is dependent on training, education, availability of follow-up and extension services. Access to educational opportunities by women is needed to free them from attitudes and customs that favor men. Their awareness and skill acquisition through education could spur active participation in development activities (Shibanda \& Seru, 2002). In Western Kenya, lack of these services has accounted for an approximately $30 \%$ productivity loss in food provision (Buvinic, 1997).

Because women's groups in the rural areas in Kenya rely frequently on agricultural or health extension workers for their information and training needs, the potential for information bias exists that may focus more on agriculture or health and less on critical areas like education and training to meet vocational needs of women (Herz, 1989; Mutua-Kombo, 2001; Srujana, 1996; Steeves, 1996).

There have been a number of valuable studies of women's groups in Kenya all of which present evidence about the role of women's groups in rural development. 
Chronologically (most recent to oldest), the following studies are examples: Freeman, Ellis, \& Allison, 2004; Buvinic, 1997; Srujana, 1996; Karani, 1987; Thomas, 1988;

Thomas, 1987; Mwaniki, 1986; and Lanier, 1968. Frequently, the studies about women's groups in Kenya have dwelled on topics such as agriculture (Mwaniki, 1986), nutrition (Nichols-Casebolt, Krysik, \& Hermann-Currie, 1994), participation in rural village meetings (Mwabu \& Thorbecke, 2004), community development (Srujana, 1996), household strategies (Thomas, 1988), and information provision (Mutua-Kombo, 2001). Additionally, most of the existing literature on women's groups in Kenya is not current and much of it was reported in the 1980s, e.g., Anderson and Leiserson (1980), Feldman (1983), Herz (1989), Lanier (1968), Mackenzie (1986), Mwaniki (1986), and Thomas (1988), especially with regards to Western Kenya.

\subsubsection{What has changed since the 1980s in Kenya?}

In the whole of Kenya's post-independence history, "the HIV-AIDS pandemic ... is the single-most serious health and development challenge that Kenya has faced ... the only health problem that is believed to have reversed the significant gains made ... during the first three decades of independence" (Government of Kenya [GOK], 2003, p. 43). This pandemic transcends the health sector and "encompasses economic, social, and cultural dimensions" (p. 43). The effects of the HIV-AIDS on children and those who care for them has been devastating, therefore, the Government of Kenya promotes a multi-sectoral approach in partnership with stakeholders such as "training communities on HIV-AIDS home-based care" (p. 44) in the battle against the pandemic. The 
Government of Kenya's fourth pillar of economic development is "investment in the human capital of the poor" (p. xix) "as an important ingredient to the realization of the poverty reduction objective" (p. xx). Therefore, the Government of Kenya is committed to promoting the Micro-Small Enterprise sector by "focusing on employment creation formalization of informal activities" (p. xxi).

Additionally, the Kenyan Government realizes that "Poverty is area specific. Interventions aimed at creating employment and reducing poverty must equally be area specific. Implementation of . . . actions in the Recovery Strategy must take place either at the district, local authority or at the location levels" (p. 60). Therefore, in the spirit of 'Harambee' (i.e., a Swahili word for 'collective responsibility'), the Government of Kenya is committed to supporting "community-based initiatives [such as schools, health centers, and cattle dips], aimed at wealth creation, service provision and poverty reduction" (p. 61).

"Education is a key determinant of earnings and therefore an important exit route from poverty" (GOK, p. 39); it enables people to "take advantage of the opportunities that can improve their well-being as individuals and be able to participate more effectively in the community and markets" (p. 39). Kenya's broad objectives are to "achieve 100 percent net primary school enrollment rate and reduce disparity in access and quality of education,” (p. 40). Accordingly, free primary education has been introduced in Kenya, consistent with the development priorities outlined by the Millennium Development Goal 2, which seeks to promote universal primary education for boys and girls around the world (United Nations, 2007). 


\subsubsection{Increasing Importance of Self-Help Groups}

From the findings of Kenya Integrated Kenya Budget Survey conducted between May 2005 and May 2007 in all districts in Kenya, it was found that four out of 10 Kenyans were still living in abject poverty. The survey further revealed that majority of Kenyans borrowed money from neighbors and least from banks in the following order: 45.6\% from neighbors, $12.9 \%$ from shopkeepers, $11.4 \%$ from self-help groups; $11.9 \%$ from cooperatives, and 3.9\% from banks. Also, the rural areas had $47.9 \%$ of people who borrow from neighbors. In Western Kenya, 56.5\% people borrowed from neighbors, $11.8 \%$ from groceries or nearby shopkeepers, while $12.6 \%$ borrowed from self-help groups (The Daily Nation, 2007). This demonstrates that self-help groups play significant roles as sources of capital in rural areas of Kenya.

\subsubsection{Changing Educational and Training Needs}

However, none of these studies provides a clear picture of the educational and vocational needs that have emerged over the last decade or forecasts trends in the training needs held by women's groups in Western Kenya. Against this backdrop, this case study describes some of the educational and training needs facing women's groups in Western Kenya. Popularly referred to as Sindikiza Maisha, in Swahili, Kenya's national language, Sindikiza Maisha means "escort life," in reference to the efforts by women to address their socioeconomic constraints using collective effort, i.e., self-help groups. The study looks at some of the income-generating activities and challenges facing these associations with an emphasis on the need for business and vocational training and education to effectively prepare women to become successful entrepreneurs in Western Kenya. 


\subsubsection{Purpose of the Study}

The purpose of this study was to describe selected characteristics and perceptions of women who belonged to self-help groups in the Shaviringa Location, Vihiga District of Western Kenya. The women's perceived needs related to improving their livelihoods and economic status were of special interest to the researcher, especially for the purpose of developing recommendations for training and education programs to improve the life conditions of women in rural Kenya. The researcher conducted semi-structured, focus group interviews of 11 women's self-help groups during May and June 2007. Seven research questions were developed to guide the collection of data.

\subsubsection{Research Questions}

1. What were selected characteristics of the women's self-help groups and their members?

2. What were selected perceptions of women about the formation, primary activities, and benefits of their self-help groups?

3. What were selected perceptions of women regarding their needs for education and training as it pertained to the acquisition of vocational and business skills by members of their self-help groups?

4. What were selected perceptions of women regarding access to information and use of communication channels by members of their self-help groups? 
5. What were selected perceptions of women concerning the governance, management, and leadership of their self-help groups?

6. What were selected perceptions of women regarding the financial operations of their self-help groups?

7. What were selected perceptions of women regarding other factors that affected the performance of their self-help groups (e.g., marketing of products and services, culturally rooted gender bias, ways of improving their groups, and mobility or transport issues)?

\subsubsection{Profile and Description of Study Area}

Western Kenya is a densely populated region, and the threats to land resources are compounded by the need to increase food production and reduce poverty (Noordin, Niang, Jama, \& Nyasimi, 2001). Per the 1999 Government of Kenya national census, Vihiga District of Western Kenya had a population of 498,883 with 886 people per square kilometer (GOK, 2001). The Vihiga District lies between 1300m and 1500m above sea level with properly drained soils for the growing of both cash and food crops. Summary census information for Shaviringa Location is presented in Table 1. The area has a bimodal rainfall distribution pattern (i.e., "wet or monsoon seasons") that ranges between $1800 \mathrm{~mm}$ and $2000 \mathrm{~mm}$ of rain (Waithaka, Thornton, Herrero, \& Shepherd, 2006). 
Table 1:

1999 and 2006 Projected Kenya National Census Statistics for Shaviringa Location, Tiriki East Division, Vihiga District of Western Kenya (Source: Government of Kenya National Census, Vihiga District)

\begin{tabular}{lcllll}
\hline \multicolumn{1}{c}{1999} & & & \multicolumn{2}{c}{ Projected 2006 } \\
\hline Male & Female & Total & Male & Female & Total \\
16,367 & 18,203 & 34,570 & 19,600 & 22,535 & 42,135 \\
\hline
\end{tabular}

Tea and maize (corn) are commonly grown. The predominant livestock is the local Zebu cattle that are kept on free grazing systems. However, farmers experience poor access to markets for their products (Waithaka, et al., 2006). On average there are 6 to 15 persons depending on about 0.5 to 0.89 hectares of land, which results in overdependence on subsistence farming (Kristjanson, Krishna, Radeny, \& Nindo, 2004; Waithaka, et al., 2006). As a result, the poverty incidences in Vihiga are among the highest in Kenya with $60 \%$ of households below the poverty line (Kristjanson, et al., 2004; Waithaka, et al., 2006). Farming is hampered by declining soil fertility, shortages of fodder and fuel wood, low yield, and low income from agricultural activities. Due to widespread poverty among the citizens, persistent food insecurity, significant rural-urban migration rates, and high incidences of environmental degradation are common (Noordin et al., 2001). The average daily income in 2005 was KSh 56 (less than 1 USD), while the total annual income averaged Ksh 17,024 (about \$266 USD depending on the current exchange rate) which comes from daily wages, remittances, or the sale of food or cash crops (Waithaka et al.).

Due to overuse, the land resources have been depleted of their nutrient value and farmers have inadequate access to farm inputs and markets for their subsistence products (Waithaka, et al.). Noordin et al. (2001) argued that in Western Kenya, "attainment of food security is intrinsically linked with reversing agricultural stagnation, safeguarding 
the natural resources, slowing population growth rates, combating the negative impacts of the HIV-AIDS pandemic on local communities, and reducing poverty in the region" (p. 509). The study was based in Shaviringa Location, Tiriki East Division, Vihiga District which lies between longitude $34^{\circ} 30^{\prime}$ East and $35^{\circ} 0^{\prime}$ East and between $0^{\circ}$ and $0^{\circ} 15^{\prime}$ North of Western Kenya (see Figure 1).

Vihiga District, Western Province

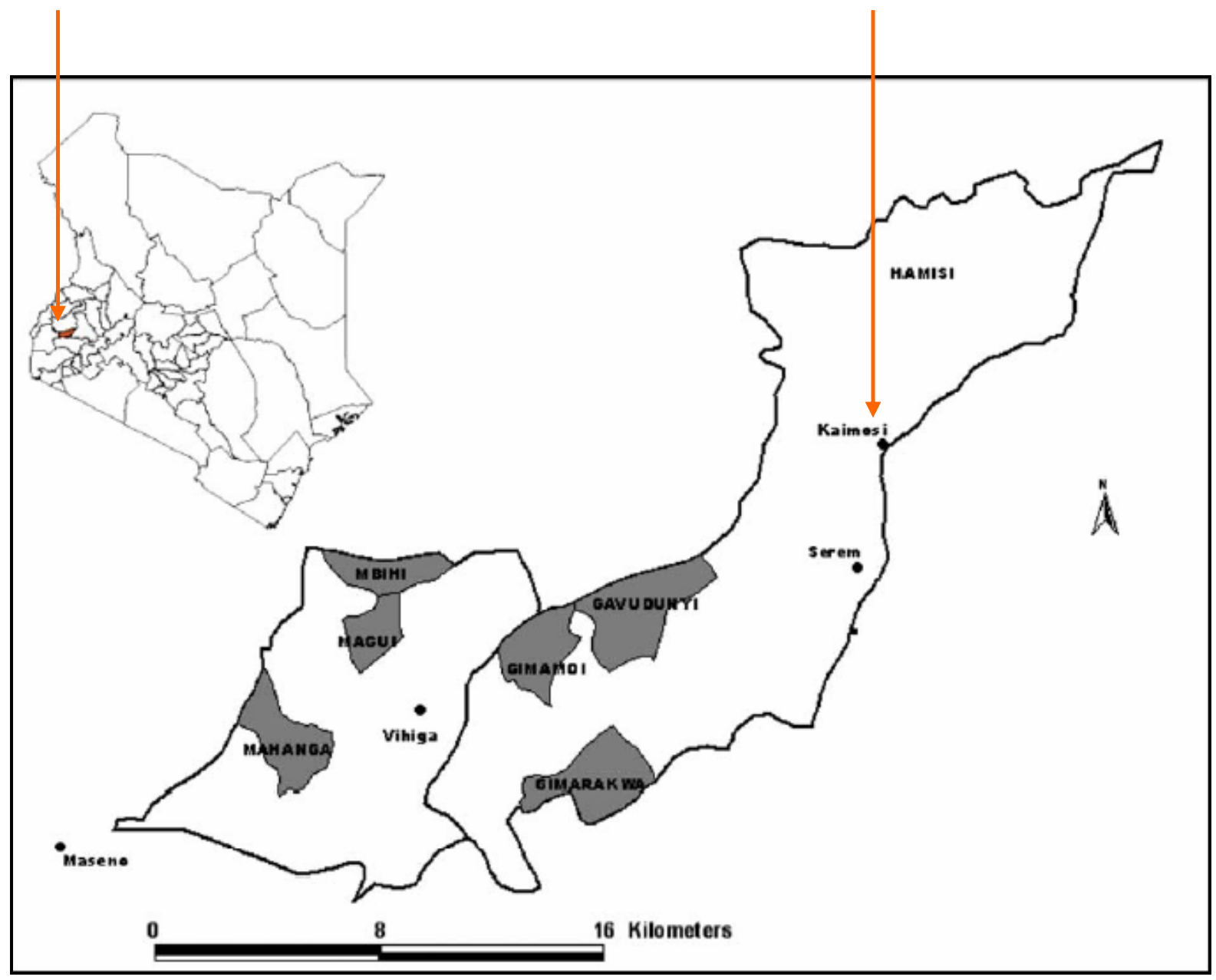

Figure 1: Map of Kenya showing Vihiga District (inset) and project location (Adapted from Waithaka et al., 2006). 


\subsubsection{Limitations of this study}

For the purpose of this study, the following assumptions were made:

1. Participants in this study would be truthful and honest in their opinions.

2. All members invited to the interviews would get an equal opportunity to participate and express their views freely.

3. The Chief of Shaviringa Location and her Deputy were the best officials (i.e., knowledgeable and reliable), to inform the researcher about appropriate women's self-help groups to interview for purpose of the study. 


\subsubsection{Glossary of Terms}

Case Study Methodology: Involves an "in-depth exploration of a bounded system (e.g. an activity, an event, a process, or an individual) based on extensive data collection" (Creswell, 2005, p. 589).

Community Development: "Involves purposive, positive, and structure-oriented actions, and exists in the efforts, as well as in the achievements, of people working together to address their shared interests and solve their common problems" (Theodori, 2005, pp. 665-666).

Education: General type of education that is homogenous in nature and prepares learners to changing economic and labor forces in the society (Oketch, 2007).

Entrepreneurship: Is a process that involves the creation and recognition of value or opportunities by people or organizations operating together, through the application of creative or innovative ideas, drive, and readiness to face risks and challenges (BentGoodley, 2002).

Income-Generating Activities: The informal occupations and activities that women engage in through their self-help groups so as to empower themselves economically to mitigate poverty in rural areas where they live. They include the sale of surplus production, petty trade, fast food sales, handicraft production, bee-keeping, brick-making, poultry-keeping, and small-scale sewing and tailoring projects (Ashley \& Maxwell, 2001; Feldman, 1983; Kamar, 1999; Karani, 1987; Karega, 1996; Srujana, 1996). Informal Institutions/Networks: Innovative informal groups that women form and use to complement their efforts in fighting poverty through the provision of low-scale goods and services thus contributing to livelihood diversification in rural African communities 
(Besley \& Burgess, 2003; Kempe, 2004; Lanier, 1968; Liedholm, McPherson, \& Chuta, 1994; Mwabu \& Thorbecke, 2004; Snow \& Buss, 2001).

Kenya: A multi-ethnic East African country famous for its scenic landscapes and immense wildlife resources. The Capital City is Nairobi, and the total area is 582,646 sq km (224,961 sq mi). English and Swahili are the official languages. The equator passes in the middle of the country. It is bordered on the east by Somalia and the Indian Ocean, north by Ethiopia, Sudan to the northwest, Uganda and Lake Victoria to the west, and Tanzania to the south. The country attained its independence from Great Britain in 1963 and is a member of the Commonwealth of Nations (Encyclopædia Britannica, 2007). Local: Pertaining to the village level of a particular rural or urban place or area homebased production (Helmore \& Singh, 2001).

Poverty: A condition that results in the denial of the opportunities and choices most basic to human life such as the choice to lead a long, healthy, and creative life with dignity, self-esteem, and respect from others. It results in vulnerability, social isolation, insecurity, and voicelessness (Dudwick, Gomart, Marc, \& Kuehnast, 2003; Fukuda-Parr, 1999; Helmore \& Singh, 2001).

Self-Help: The notion that drives the collective responsibility in women's groups that ultimately accords women a chance to enhance their status as women and contribute to mitigating community needs at the small-scale level such as health clinics, schools, wells, and cattle dips (Barbara, 1987; Snow \& Buss, 2001; Srujana, 1996).

Semi-Structured Interview: A type of interview that includes closed-ended and openended questions (Creswell, 1995). 
Structural Adjustment Programs (SAPs): Spending plans at the domestic level that include a reduction in the provision of services such as health, education, and other social programs; they are often promulgated by international agencies like the World Bank and the International Monetary Fund (IMF) to enable the repayment of loans by developing countries (Chossudovsky, 1998; Mbugua-Murithi, 1997; Weatherby, Evans, Gooden, Long, \& Reed, 2003).

Table Banking: As explained by the women's self-help groups in Western Kenya, it involves the posting together of little amounts of money which are then used to lend members with an interest charged between $10 \%$ to $20 \%$, i.e., depending on the group. The repayments are never lost as members guarantee one another and ensure repayments are made in a timely manner.

Trade School: In the Kenyan context, a trade school is also known as a vocational or polytechnic school. It provides vocational education and training in skills needed to perform certain jobs or trades such as carpentry, architectural drafting, dressmaking, electrical work, foundry work, machine trades, masonry, painting, and welding (Greenberg, 2007; Oketch, 2007).

Vocational Training: A variety of learning practices that are applicable to work and may take place in a range of learning contexts at an institution or at the workplace. This type of learning enables one to develop skills that are appropriate for particular occupations. Generally, this type of training is intended to prepare learners for direct labor market entry. Commonly used by African countries to prepare youth to be self-employed in the rural and urban informal sectors (Oketch, 2007). 
Women's Groups: Relatively small, local community-based groups formed for the purpose of working collectively and socializing on a regular basis, and to encourage selfhelp opportunities to improve the welfare of women (Srujana, 1996). 


\section{CHAPTER II}

\section{REVIEW OF LITERATURE}

\subsubsection{Summary}

The aim of this study was to describe selected characteristics and perceptions held by women who are members of self-help groups in the Shaviringa Location, Vihiga District of Western Kenya. Due to the challenges of providing for their families and themselves in an environment with limited income, these women have resorted to the formation of informal networks (i.e., self-help groups) to mitigate some of their socioeconomic challenges collectively (Buvinic, 1997; Neitzert, 1996; Snow \& Buss, 2001; Thomas, 1987). Their common mode of operation is the establishment of incomegenerating activities that are supported by group members' contributions.

Therefore, this study sought to describe what women, who were members of these associations, perceived to be their needs and how the performance of their associations could be improved. An improvement in their performance as groups could improve their lives. Special emphasis was focused on the educational and training needs of the women's self-help groups and the development of recommendations that could be used to improve the functioning of groups in the Shaviringa Location, Vihiga District of Western Kenya. The researcher conducted semi-structured, focus group interviews (Creswell, 2005; Krueger, 2000; Patton, 1999) of 11 women's self-help groups during May and June 
2007 to answer seven research questions that guided the collection of data. The interview questionnaire consisted of 43 items. Two research assistants worked with the researcher to carry out the interviews. The researcher tabulated and summarized the data.

\section{Purpose of the Study}

The purpose of this study was to describe selected characteristics and perceptions of women who belonged to self-help groups in the Shaviringa Location, Vihiga District of Western Kenya. The women's perceived needs related to improving their livelihoods and economic status were of special interest to the researcher, especially for the purpose of developing recommendations for training and education programs to improve the life conditions of women in rural Kenya. The researcher conducted semi-structured, focus group interviews of 11 women's self-help groups during May and June 2007. Seven research questions were developed to guide the collection of data.

\section{Research Questions}

1. What were selected characteristics of the women's self-help groups and their members?

2. What were selected perceptions of women about the formation, primary activities, and benefits of their self-help groups?

3. What were selected perceptions of women regarding their needs for education and training as it pertained to the acquisition of vocational and business skills by members of their self-help groups?

4. What were selected perceptions of women regarding access to information and use of communication channels by members of their self-help groups? 
5. What were selected perceptions of women concerning the governance, management, and leadership of their self-help groups?

6. What were selected perceptions of women regarding the financial operations of their self-help groups?

7. What were selected perceptions of women regarding other factors that affected the performance of their self-help groups (e.g., marketing of products and services, culturally rooted gender bias, ways of improving their groups, and mobility or transport issues)?

\subsubsection{General Aspects of Poverty in the Developing World}

The multidimensional definition of poverty includes the denial of the opportunities and choices most basic to human life such as the choice to lead a long, healthy, and creative life with dignity, self-esteem, and respect from others (Fukuda-Parr, 1999). According to the Global Poverty Report (2000), more than three billion people are living on less than two USD per day while close to 1.2 billion people are living on less than one USD a day (Morduch, 1999). The poor are deprived of not just income but also of opportunities, sometimes because of low capabilities or social exclusion (Global Poverty Report). Hulme and Shepherd (2003) contended that "many people are born poor, stay poor, die poor, and have children that have a high probability of impoverishment" (p. 417). This is a major challenge to most policy-makers who are faced with the task of improving people's lives (Morduch).

Poverty became entrenched in the international agenda in the 1990s (Global Poverty Report, 2000; White, 1999). At the Millennium Summit for the United Nations in 
2000, world leaders set an ambitious agenda for improving human welfare through the Millennium Development Goals (MDGs). One central goal is the halving of poverty by 2015 in the developing world (Besley \& Burgess, 2003). In 2001, the Millennium Challenge Account (MCA) was created to come up with strict standards of accountability and performance for poor countries (Sperling \& Hart, 2003). However, the progress of meeting these goals has been slower and uneven across the regions; some regions, such as Africa, have regressed due to the effects of the Acquired Immune Deficiency Syndrome (AIDS) pandemic on their populations (Global Poverty Report).

Sub-Saharan Africa is among the areas where poverty is geographically concentrated, and it is so pervasive that many of the policies concerned with poverty alleviation encompass practically most of the development plans (Bardhan, 1996; Collier \& Gunning, 1999). Both macro and microeconomic strategies are the reason for Africa's stagnating growth (Christiansen, Lionel, \& Paternostro, 2003). For instance, the International Monetary Fund and the World Bank's policies were predicated on economic reconstruction, though their structural adjustment programs (SAPs) have been contributing to the destabilization of national economies in many developing countries. Local communities continue to be impoverished by these macroeconomic reforms (Chossudovsky, 1998). The reforms have contributed to the elimination of social programs and the diminution of the state's role in fighting poverty. For example in India, farmers committed suicide following months of implementation of the New Economic Policy by these institutions (Chossudovsky, 1998; Helmore \& Singh, 2001). India's case is a clear demonstration that some development interventions can indeed be tragic (Helmore \& Singh). 
According to Seidman (1977), the desire of most African countries after attaining their political independence was to industrialize and provide meaningful employment opportunities and improved standards of living for their people. Extended colonial policies discouraged traditional handicraft industries and set the stage for rural-urban migration by many rural citizens who chose to migrate in search of jobs or some of the vaunted benefits of technological advancement (Seidman, 1977). According to Besley and Burgess (2003), between 1990 and 1998, various regions exhibited different trajectories of poverty. In East Asia, the rates of poverty decreased from $27.5 \%$ to $15.3 \%$; this resulted in use of the term - the Asian Miracle. In contrast, the rates of poverty in Africa continue to be stagnant with a slight change from $47.6 \%$ to $46.3 \%$. It was also in the period from 1990 to 1998 that about "50 million people" were added to Africa's poverty roll, which Besley and Burgess referred to as the "African tragedy" (p. 5). As a consequence, African policy-makers face the growing challenge of providing employment for an increasing population of impoverished citizens (Neitzert, 1996). Frequently, this population engages in production that it is often referred to as the invisible labor force, informal sector, home-based production, petty trading, or small holder farming (Buvinic, 1997).

Therefore, fighting poverty has become both a moral imperative and a necessity for a stable world order (Global Poverty Report, 2000). Decision-making in the hands of those with localized information can be very important; for example, local community organizations with stable membership and well-developed mechanisms to disseminate information among their members have the potential to provide more efficient coordination than either the state or the market (Bardhan, 1996). Policy initiatives need to 
focus on investing in human capital through educational or health programs with an emphasis on women and children who make up the majority of the poor (Kempe, 2004).

One of the most stubborn problems in our modern times is persistent widespread rural poverty in many developing countries. Rural communities are challenged by the task of organizing themselves for effective participation in economic and social development while ensuring equitable distribution of the benefits (Thomas, 1987). The world's rural populations depend on many non-farm activities as a source of employment, income generation, and improved living conditions. It is these kinds of activities that help localize employment and stimulate a degree of decentralization of urban growth (Anderson \& Leiserson, 1980). Rural development in Africa is constrained by the neglect of the non-farm sector, but this could be corrected by improving the profitability of non-farm enterprises so as to stem rural-urban migration and thus control urban poverty increases (Mwabu \& Thorbecke, 2004). Most important, an effective rural poverty reduction strategy must harness the non-farm sector's potential (Ashley \& Maxwell, 2001).

\subsubsection{Feminization of Poverty}

Globally, women face more restrictions on their choices and opportunities than men do; for instance, unequal opportunity in school restricts opportunities for employment and also a creative life. Such gender bias has led to lower survival for women despite their biological advantage (Fukuda-Parr, 1999). Because globalization is a common theme in developing national alternatives, it is important to broadly examine the economic well-being of women in terms of the global agenda. The decisions that take 
place in one country can have consequences on another country or an entire region (Nichols-Casebolt, Krysik, \& Hermann-Currie, 1994).

According to the United Nations (2001), the poorest of the world's poor are women and they comprise over two-thirds of the people living on less than one USD a day. Women experience higher incidences of income poverty, and over time this condition seems to be increasing (Cagatay, 1998; Northrop, 1990). Lack of proper training and skills further exacerbates women's poverty causing a vicious cycle of impoverishment from one generation of women to the next. This pattern of women being vulnerable to poverty runs from childhood to old-age; in developing countries, older women have a greater need for medical, social, and economic assistance (NicholsCasebolt et al., 1994). The result is a growing global trend of poverty which Buvinic (1997), Northrop, (1990), and Pearce (1992), refer to as the feminization of poverty. This trend is often linked with female-headed households (Chant, 2006; Marcoux, 1998; Northrop, 1990). Because women are major economic actors, heads of households, and mothers, their impoverishment slows growth and results in spirals of poverty, population growth, and environmental degradation (Buvinic, 1997). However, incomes should not be the sole measure of poverty. By focusing on incomes or the household as a unit alone, Fukuda-Parr (1999) argued that this measure masks the extent of poverty among women and ignores intra-household disparities.

A study of rural poverty in 41 developing countries revealed that more women in rural communities are poor and continue to shoulder economic burdens as farmers, abandoned wives, young widows, or young mothers (Buvinic). Even though a global economy spells greater potentials for development, an even greater potential for 
exploitation of women and girls exists (Nichols-Casebolt et al., 1994). Women are the major "breadwinners" in most places around the world and a majority of households rely on their income (Nichols-Casebolt et al.). However, they face special social and economic constraints that perpetuate a cycle of low-education and low-paying jobs from one generation of women to another. Interventions at the household level seem to be inadequate, and thus the need to expand their socio-economic opportunities exists (Bardhan, 1996). Livelihood diversification is important both to governmental and nongovernmental agencies in Africa (Ashley \& Maxwell, 2001). Inadequate access to credit for engaging in small scale agriculture, income-generating activities, and access to markets for sale of goods and services produced by the rural poor are some of the factors responsible for poverty in much of Africa (Kempe, 2004). Economic growth for the poor can be realized by expanding their opportunities for productive and remunerative employment, including self-employment on farms and in artisan shops (Ashley \& Maxwell, 2001; Bardhan, 1996).

Consequently, small scale economic enterprises have become major sources of income in the rural areas of African economies accounting for 20 to $45 \%$ of the full-time employment and 30 to $50 \%$ of the rural household income (Liedholm, McPherson, \& Chuta, 1994). Such small enterprise developments have the potential of absorbing labor in the least developed countries (Steel \& Takagi, 1983). Micro-finance institutions such as the Grameen Bank of Bangladesh have been heralded as innovative for the delivery of credit to the poor, including women; such innovative institutions have the potential of lowering inequality and raising output simultaneously (Besley \& Burgess, 2003). Conversely, many international development aid agencies are now embracing such 
informal institutions because of their role in economic development, especially in SubSaharan Africa. They help complement bottom-up community development and correct government failures where national policies may have stymied growth (Snow \& Buss, 2001).

The Micro Enterprise Summit in 1997 resolved to provide the world's poor with credit for income-generating activities and was aimed at helping women in their global poverty alleviation efforts (Mayoux, 1999; Perry, 2002). The use of locally appropriate technology generates more employment, satisfies the demand for simple manufactures, and raises the income per capita (Steel \& Takagi, 1983). Expanding the opportunities for credit, for example, can help the poor to invest in education as a way to climb out of poverty (Bardhan, 1996), i.e., through activities based on local resources or skills such as crafts and services linked to tourism and crops that rely on near-farm processing (Ashley \& Maxwell, 2001). With very modest lines of credit, small farmers and artisans are likely to become more economically viable and enlarge their scale of production, take up more high-return, high-risk projects or occupational choices, and, in general, avoid the negative consequences associated with many myopic policies (Bardhan).

\subsubsection{Women's “Self-Help” Groups and Associations}

Formal employment has been decreasing over the years and, consequently, the informal sector has been absorbing many jobs in Kenya (Neitzert, 1996). Rural areas are perpetually faced with a shortage of working capital and in response women have now resorted to the use of informal institutions popularly known as women's self-help groups to complement their efforts to fight poverty (Lanier, 1968; Snow \& Buss, 2001). 
Common problems frequently result in common solutions; this is the reason women in less developed countries devise innovative strategies to address their problems and also inform the policy-makers (Nichols-Casebolt et al., 1994). In Costa Rica and India, women's income-generating groups were found to have provided women with sources of income, improved their self esteem and personal development, and increased their independence and bargaining power within their families (Nichols-Casebolt et al.).

Africa is the world's region with the most extensive female solidarity organizations, i.e., an indication of the importance women hold regarding their ties and associations outside of household boundaries (Thomas, 1988). Such affiliations create new opportunities to generate, save, and invest income and assist women in effectively responding to the dynamic socio-economic changes as individuals, family, groups, or as a community (Thomas). Among the poor, these kinds of "institutions" provide a strong indicator that the citizens of rural Africa need credit (Snow \& Buss, 2001). These informal networks, including groups devoted to providing low-scale goods and services, contribute significantly to Africa's rural livelihood development (Mwabu \& Thorbecke, 2004). They are a source of employment and economic growth exhibiting a vibrancy that is an expression of "bottom-up," private entrepreneurship (Kempe, 2004).

These small informal women's groups and associations could be powerful vehicles for the diversification of livelihoods in rural African communities (Mwabu \& Thorbecke, 2004). Governments are now acknowledging such contributions to their economy; for instance, in 1994, micro-small enterprises contributed close to $15 \%$ of Kenya's national income (Daniels \& Mead, 1998). Similarly, failure of the financial institutions to deliver credit to the poor has led to a proliferation of informal networks, 
which operate on the basis of trust and intimate knowledge (Kempe, 2004). Community groups are popular institutions in Kenyan villages and take the forms of women's groups, youth groups, or burial groups. Churches are also among the most helpful institutions in rural communities in Kenya; through missions, they provide services that the public service may have failed to provide (Freeman, Ellis, \& Allison, 2004).

Rural women band together in village centers, churches, or school buildings to raise standards and change their life conditions, including instruction in literacy, vocational training, public speaking, leadership, agricultural methods, sanitation, family planning, voting, and budgeting. Such efforts are gradually making changes in their self esteem, ambition, and determination in one village after another (Freeman et al., 2004; Lanier, 1968; Noordin, Niang, Jama, \& Nyasimi, 2001; Thomas, 1988). In India, women who rarely had opportunities to meet with each other began using government-sponsored literacy classes to share personal experiences and family problems. Such cases were the sources of a grassroots movement that is beginning to influence local and state policies for improving the lives of women (Nichols-Casebolt et al., 1994).

Structural adjustment programs of the International Monetary Fund (IMF) and the World Bank have shifted responsibility from the government to the households. In turn, women's responses have led to their harnessing of resources within their own homes (Mbugua-Murithi, 1997). In Africa, women self-help groups are popular in Kenya (Buvinic, 1997; Clark, 1984; Kiteme, 1992; Mwaniki, 1986; Thomas, 1988), Malawi (Ettema, 1984), Nigeria (Okonjo, 1979), Senegal (Perry, 2002), and Swaziland (Kamalkhani, 1991). 


\subsubsection{Rural Women in Kenya}

As of 2001, Kenya had a population of about 30.7 million, a $2.4 \%$ annual growth rate, and $67 \%$ of its citizens lived in rural areas (Freeman et al., 2004). The rural poverty rate in Kenya in 1999 was 46.4\% (Ashley \& Maxwell, 2001). Women comprise over $50 \%$ of the rural Kenyan population and many rural households are female-headed due to the absence of the husband for long periods or death. Hence, women are left with the responsibilities of feeding the family and generating income for the entire household (Feldman, 1983; Kiteme, 1992; Srujana, 1996).

Traditionally, Kenyan societies practiced division of labor between men and women; men hunted while women were mainly gatherers of fruits and vegetables (Srujana). However, the colonial economy disrupted the traditional patterns of task allocation on the farm and adversely affected the existing female autonomy in Kenya (Srujana). Cash crops upset the division of labor among men and women as more women were drawn to what was originally men's work for wages. Moreover, the arrest of men during the fight for Kenya's independence made women become independent but confined to subsistence agriculture while men took over cash crop production. European education changed men's attitudes about agriculture and they came increasingly to consider it to be "women's work" while educational opportunities favored boys over girls (Srujana). By tradition, Kenyan women helped each other in times of need such as death, sickness, and childbirth while family responsibilities such as farming were shared. The traditional roles of women included wife, mother, child bearer, caretaker, and food provider (Karani, 1987). However, these traditions have since been disrupted by the 
effects of modernization; the roles of women in Kenya frequently reflect their levels of education (Karani).

\subsubsection{The Concept of Women's Groups in Kenya}

Kenya's local self-help development efforts are predicated on the spirit of Harambee - a Swahili word that connotes community efforts for a common goal (Thomas, 1988). According to Feldman (1983), Kenya joined the initial International Labor Organization (ILO) efforts in 1977 to realize the importance of women as a target group for fighting poverty. This was in view of the significant contributions women make to Kenya's economy through their involvement in agricultural production and provision of wage labor in small farms, factories, and plantations (Feldman, 1983). On realizing the importance of women groups, the Kenya government created a Women's Bureau in 1976 because women's groups form institutions that are "of popular participation for development" (Srujana, 1996, p. 7).

Because not all food can be grown readily, women in Kenya are forced to engage in several income-generating activities to enable them to purchase foodstuffs that they can not grow easily. These activities may include the sale of surplus production, petty trade, local beer brewing, fast food sales, or tobacco selling (Srujana). Also, male exodus from the countryside caused a drain on the rural labor force leaving women as the de facto leaders of households (Kiteme, 1992). However, the problems they experience have become seeds to their solutions in some cases, i.e., small-scale business enterprises (Kiteme, 1992). As household heads, this position is disadvantageous economically, socially, legally, and culturally. Due to these disadvantages, women are forced to design 
strategies to overcome problems, hence the formation of women's groups as a strategy to meet their educational and socioeconomic needs have proliferated (Mbugua-Murithi, 1997).

Srujana (1996) defined Women's Groups as follows:

The term women's groups, generally refer[s] to relatively small local community based groups formed for the purpose of working collectively and socializing on a regular basis. The groups encourage self-help, offering individual members an opportunity to improve their welfare and those of their families. (p. 30)

\subsubsection{Objectives of Today's Women's Groups}

Historically, women's groups were created as work parties in response to their common needs in the division of labor in agriculture (Feldman, 1983). Modern women's group's objectives now focus more on income generation projects rather than welfare activities. They are multi-purpose and combine mutual financial assistance in the form of rotating credit associations to provide the means to pursue social, educational, and economic activities (Feldman, 1983; Mbugua-Murithi, 1997). This is mainly in response to the socioeconomic changes taking place in the rural areas that negatively impact women (Mackenzie, 1986; Mbugua-Murithi, 1997). The self-help “spirit” puts emphasis on small community concerns such as health clinics, wells, cattle dips, fish ponds, community halls, feeder roads, schools, and village polytechnics (Karani, 1987; Srujana, 1996; Thomas, 1987) as well as the establishment of adult literacy programs (Srujana, 1996). Income-generating projects include handicrafts, bee-keeping, brick-making, poultry, livestock, and petty trade (Kamar, 1999; Karani; Karega, 1996). Implementing 
such development projects in their communities requires organizational and leadership skills in making decisions, income generation, and mobilization of community members. Thus, it is important to examine the roles, functions, and pertinent issues arising from the use of such local organizations to promote development (Thomas, 1987).

Non-agricultural activities could include consumer shops, handicraft production, residential housing for rentals, small-scale sewing and tailoring, corn-milling, or a bakery. These are the key ventures that involve small-scale enterprises and "require capital and some untried markets" (Feldman, 1983, p. 83). The handicrafts are considered "easy to enter" (p. 83), although they rely on markets that are uncertain. In the commercial enterprises of Kenya's rural markets, women traders are intertwined with the socioeconomic activities and daily lives of people in the countryside. They supplement the food supply and provide financial assistance and other benefits to the community (Kiteme, 1992).

For an equitable distribution of its economic resources, Kenya uses a district-level focus which has significant implications for women who are the majority in rural areas and are members of organized groups (Steeves, 1996). Women's groups' projects in Kenya serve as key participatory organizations for improving the lives of women and making them self-dependent. Based on their numbers and potential votes, they form an essential base that can elicit the political support that is needed to prosper (Srujana, 1996). The groups are viewed by the government and private agencies as excellent agents for initiating development (Kane, Walsh, \& Nelson, 1991). Through such informal associations, non-governmental organizations (NGOs) have played a major role in the 
transformation of villages through the provision of piped water, water wells, and microcredit access (Freeman, Ellis, \& Allison, 2004).

Thomas (1988) is emphatic about the need of understanding such associations to avoid creating programs that would undermine women or create general policies that do not account for their specific local needs. Similarly, Karega (1996) asserted that these groups should not just be viewed as mere tools of welfare because they engage in income generation activities in the informal sector. They demonstrate an entrepreneurial behavioral pattern where they produce for the market, are innovative, take risks, develop and accumulate capital, and reinvest and market products in business enterprises that are compatible with their daily enterprises. This reveals that capital and profit formation occurs from these types of enterprises. In some instances, women use their own resources to support group activities (Karega, 1996).

\subsubsection{Women's Work in Agriculture in Kenya}

Apart from fetching firewood, water, feeding and caring for the family, nearly all women in the rural areas are engaged in some form of agricultural activity (Kamar, 1999). These women contribute significantly to economic development despite being accorded a peripheral role in the making of policy decisions that concern them. In spite of their high numbers as well as increased activity in rural areas, it is obvious that the development decisions or benefits are not fairly distributed (Steeves, 1996). Even as farmers, casual laborers, formal or informal employees, theirs is a subordinate role that is sustained by both legislation and cultural beliefs (Feldman, 1983). As a result, the major problem facing rural women is not the lack of involvement in development, but a 
development emphasis that confines them both to poverty and general subordination due to their gender (Feldman, 1983; Mwaniki, 1986).

Women play a vital role in the agriculture of Kenya but they are still disadvantaged by the lack of land ownership, security for loans, limited access to income from agriculture (Noordin, Niang, Jama, \& Nyasimi, 2001), and are “. . . untouched by agricultural training programs" (Feldman, 1983, p.72). Land ownership is still a preserve of men yet women provide most of the labor for subsistence farming which makes women responsible largely for it (Srujana, 1996). Women's projects are not integrated into the local agricultural development plans; instead, they are considered as ancillary enterprises for raising income. This makes it difficult for women's groups to access government assistance, bank loans, or grants (Feldman, 1983). The lack of capital and the relegation of women's projects or initiatives as short term solutions to their problems and thus peripheral to nation's mainstream economic development plans affects attempts to change the economic status of women (Kane et al., 2001; Mwaniki, 1986; Srujana, 1996).

\subsubsection{Importance of Women's Self-Help Groups to Their Communities}

There are numerous benefits for communities that accrue out of women participating in self-help groups such as the provision of education, collective labor, mutual support, and income. Through group activities and dynamics, skills can be acquired in areas such as accounting and management of group affairs and projects (Mbugua-Murithi, 1997). Women's groups act as convenient organizational structures that are appropriate for use with rural development approaches (Srujana, 1996). According to (Noordin, Niang, Jama, \& Nyasimi, 2001), they help disseminate information to their members in a participatory manner through groups' activities. When 
used by external facilitators or development agents, they act as good entry points for understanding village development needs and problems. They are useful instruments for changing the attitudes of members towards taboos, myths, farming practices, and overall local development (Noordin et al. 2001).

Srujana (1996) argued that women's groups are important connections between the local people and the government because of their ability to mobilize communities for development. Kamar (1999) affirms that groups help to mobilize collective action for activities such as soil or water conservation and fertility management. As a result, they create cohesiveness and togetherness among community members (Noordin et al.). However, Srujana (1996) is antithetical about the politicization of women's groups by politicians to serve their ends without solving the needs of women. From a development perspective, movements such as women's groups offer alternatives to the macro, "topdown" development that are both realistic and viable; because, frequently, they thrive on small amounts of capital input. For instance, the average amount of capital owned by women's groups varies significantly from less than Ksh 10,000 to upwards of Ksh 20,000 (1 USD = Kenya Shillings 67.0267; Business: Central Bank . . , 2007). (Foreign Exchange rates are unstable and fluctuate, thus, they reflect the current market and international rates.)

But with such little amounts of capital, women's groups have been able to undertake various development projects (Srujana). Based on the foregoing, Srujana refutes the popular belief about developing countries such as Kenya that lack of development is due to a deficit of capital or labor force. Even though lack of capital is a constraint, women's groups in Kenya are a testimony that capital is not necessarily a 
constraint to development, but with some incentives from the government and nongovernmental agencies, they can help steer the nation to development and through projects based on the principle of sustainable impacts and outcomes (Srujana).

\subsubsection{Obstacles facing Women's Groups in Kenya}

\subsubsection{Inadequate Income}

Among women's groups, income generation is popular but also the most problematic because many groups fail to generate significant income for their members and the continuation of activities (Kane, Walsh, \& Nelson, 1991). For example, most groups are impeded by inadequate income, and, hence, the inability to own property that could be used as collateral if they wished to acquire additional credit (Mbugua-Murithi, 1997). Organization is also a constraining factor which manifests itself as a lack of records or poor bookkeeping and inadequate organizational and management skills (Mbugua-Murithi, 1997; Srujana, 1996).

\subsubsection{Lack of information}

According to Mutua-Kombo (2001), information is only relevant if it serves the users' needs, but if it does not, then it is insignificant. Women's groups in rural areas do not have ready access to information mainly due to the ways in which rural information services are coordinated. Steeves (1996) emphasized a communication and information policy based on gender equity that encompasses employment, information access, information representation and content, and the appropriate selection of technologies. Women's groups are formed with the aim of alleviating impoverished economic and 
social conditions that characterize many rural areas, so their information needs must be addressed and the requisite information made available toward that end (Mutua-Kombo). Women's groups have special knowledge of their needs and some of the pertinent information that could be used to satisfy those needs. Additionally, women possess crucial technical knowledge which has been neglected, especially with regards to agriculture (Steeves, 1996). Mutua-Kombo (2001) asserted that information providers and experts must pay attention to the unique information needs of women's groups and how best they could use information.

Even with the enormous contribution to development around the world, women are still disadvantaged by the lack of information and resources needed to improve their socio-economic status (Herz, 1989). In many rural areas, it is largely a result of previous government failures in rural information provision which creates a culture of mistrust on the part of rural citizens who may have little trust for government agents at the outset (Mutua-Kombo, 2001). Herz (1989) argued that national policies promote equality of opportunities regardless of gender; yet, women still lag behind men in many aspects of life. Traditional constraints also limit the opportunities of women. This results in a vicious cycle of poverty that depresses both productivity and welfare among women, their children, and their communities (Herz).

Consequently, women's groups have to rely on agricultural and health extension officers for information who are frequently underfunded in the rural areas. This can create an information bias that focuses on agriculture or health and less on management or other crucial areas like education and training that extends beyond agricultural information needs (Mutua-Kombo). Moreover, because women are conversant with 
"traditional forms of media and communication," women's groups can be resourceful in "determining strategies to increase media and information access by women and other marginalized groups" (Steeves, 1996, p. 170).

\subsubsection{Extension and Training}

Farmer training affects productivity yet there still exists differential access to training between men and women, with most of the training directed towards men. Courses for women rarely include agricultural training and female-headed farms are not accorded equal visits by extension workers as are those that are jointly headed (Feldman, 1983). They are also accorded relatively less assistance by extension officers as a result of the prejudicial attitudes prevalent in many cultures. Even on the extension staff, women are largely underrepresented, and, as a consequence, the extension programs designed for women are largely marginalized (Feldman, 1983). As a remedy, Steeves (1996) posited that the training and use of more female extension agents was needed and "making more use of the existing women's groups and networks" (p. 170) was desirable.

The agricultural extension officers from the Kenyan Ministry of Agriculture provide crucial sources of agricultural and nutritional information through individual visits or group meetings with farmers by disseminating information and education through short courses (Steeves). However, the lack of capital and inadequate follow-up by extension staff are major setbacks facing many women's groups (Kamar, 1999). In Western Kenya, it is estimated that lack of these services accounts for a $30 \%$ productivity loss in food provision (Buvinic, 1997). 
To achieve enhanced performance by community-based organizations, it is crucial for development agencies to have consistent follow-up and support mechanisms (Noordin, Niang, Jama, \& Nyasimi, 2001). In cases where follow-up is poor, the tendency exists for groups to perform dismally. However, the major constraint facing development agencies is how to sustain follow-up and extension when a project is “accomplished" (Noordin et al., 2001).

\subsubsection{Sales, Marketing, and Management Problems}

The capacity for expansion of local industries in rural areas exists, although women's groups have to contend with "the harsh competition to corner a small section of a limited market” (Feldman, 1983, p. 82). Concomitantly, many women's groups are already facing a deficiency of skills in management of their income-generating activities and projects; this applies to sales, management, duplication of projects, investment, lack of viable markets, and understanding competition (Herz, 1989). Some women's groups that received start-up loans or grants are weighed down by the repayment of the loans and lack of markets for their products; or, their activities do not seem to generate much income. And, some still face serious financial constraints even after receiving such loans. Citing the example of Kaimosi Women Group's Cottage Industry in Western Kenya, Feldman (1983) stated that,

In Kakamega, Kaimosi Women's Group, described by the District Community Development Officer as one of the 'most successful women's groups' had been given a large loan from Partnership for Productivity to buy a clay-making machine. The group had a temporary market for their pots and other handicrafts guaranteed by the National Christian Council for Kenya (NCCK), and they had 
two German volunteers who helped them with both the technical aspects of pottery and marketing. With this help they had managed to repay their loans, but the markets had dried up, and the volunteers had gone, leaving them with insufficient expertise. This forced them to reduce production because they had no profits, and therefore no money for materials. They had also experienced a decline in membership because it showed no return for a lot of effort. These kinds of projects, which were essentially small enterprises of the 'informal' sector type of a productive or non-productive nature, seem[,] for the most part[,] to have developed with a remarkable disregard for considerations such as market conditions, skilled personnel, or capital depreciation, as well as for wage levels and employment conditions of workers, or whether these latter were women. (p.

In such cases, the economic value of women's time is vulnerable to exploitation, for example, potholders from another local women's group in Western Kenya were sold in Nairobi for less than cost of the material to produce them (Buvinic, 1997). For this reason, Feldman (1983) underlines the importance of assessing the marketability of items such as handicrafts produced by women's groups in the rural areas to ascertain if indeed they are realistic and sustainable economic solutions.

\subsubsection{Inadequate Business and Vocational Training}

In a study of community-based soil and water conservation by women's groups in Kenya, training and education ranked first as the major motivating factors for the 
participation of women alongside the provision of tools, materials, and funds (Kamar, 1999). However, a dire need exists to train more women in group dynamics and team building strategies, record keeping, leadership skills, monitoring and evaluation of projects, and proposal writing. Frequently, marginal economic climates, inadequate business designs, and negative beliefs about activities of women are due to their lack of skills in business and management, or that is the perception held by some decisionmakers. As a consequence, most income-generating activities encounter dismal business performance (Kane, Walsh, \& Nelson, 1991). According to Kane et al. (1991) the immediate social and economic environment experienced at the household level can be linked to a trend which makes most women's groups struggle to operate their businesses efficiently. So, efforts must be made to strengthen women's groups' management and logistical capacity (Herz, 1989).

\subsubsection{Education and Training: What is Needed}

The means to improve the lives of women starts with education and information access (Steeves, 1996). Educating women results in positive changes in society such as smaller families, delayed marriage, longer life expectancy for children, and improved health and nutrition (Steeves). Growth and concentration in rural areas raises the demand for infrastructure services such as electricity, water supplies, roads, schooling, health, and vocational training in non-farm activities (Anderson \& Leiserson, 1980; Karani, 1987; Noordin et al., 2001; Thomas, 1988). Extension agencies and development organizations are increasingly relying on women's groups as instruments through which information regarding improved agriculture, livestock production, health, and new technology may be 
disseminated (Udvardy, 1998). However, even though women frequently are the power behind farm production, they have little background or training in agriculture (Shibanda $\&$ Seru, 2002). Kamar (1999) affirms that the success of women groups is dependent on amount of exposure to training or education and the frequency of follow-up by extension workers. Female education provides synergistic effects that increase social and economic welfare (Whitehead \& Lockwood, 1999).

Access to education opportunities by women is needed to free them from attitudes and customs that favor men. Their awareness and skill acquisition through education could spur active participation in development activities (Shibanda \& Seru, 2002). Using existing groups for training or development rather than forming new ones accelerates and enhances impact in their communities. It empowers the groups by giving them a sense of ownership over the development process (Noordin et al., 2001). Such training programs could be facilitated by international agencies, voluntary organizations, and universities. A great need for female mentors, related capacity building efforts and tailored programs exists (Shibanda \& Seru, 2002).

A significant portion of the Kenya's population, as is the case of many developing countries, lives on less than one USD a day (United Nations, 2001). Social, economic, and political issues associated with structural adjustment programs (Mbugua-Murithi, 1997; Chossudovsky, 1998) and low income from subsistence farming, together with the vagaries of HIV-AIDS, have greatly contributed to the vexing incidences of poverty in rural areas of Western Kenya (Noordin et al.). It is evident that vocational education and training could and does prepare people for productive employment opportunities. Even though vocational training has made major contribution to the creation of jobs in Kenya, 
most vocational education and training centers are located in the urban centers (House, 1984; Neitzert, 1996) and only a few in the rural areas. If a clear education and training policy were in place for marginalized groups such as youth and women, it is possible that Kenya could generate employment opportunities that contribute to poverty alleviation in its rural areas (Ziderman, 2003).

Western Kenya, specifically the Vihiga District, is one of the leading poor districts of the country. This poverty is compounded by high population growth, AIDSrelated deaths, low income from subsistence farming, and persistent food shortages. High rates of unemployment result in rural-urban migration by many adult males, leaving women and children in the rural areas. With meager incomes and high levels of illiteracy, the result is increased dependency on their "absentee husbands." Cultural practices further contribute to the marginalization of women in rural areas of Western Kenya. Efforts geared towards empowering women using informal networks in Kenya are fairly recent interventions. So, education is regarded as a crucial instrument for empowering rural women. Through community self-help organizations, women have the ability to act as their own instruments of change; this has the potential of bringing communities into closer ties with government institutions and other service providers (Noordin et al., 2001).

The existing women's groups in Western Kenya exhibit clear leadership structures that guide their income-generating activities. Education and training programs could be superimposed over the groups' existing activities in which women are involved already. Shibanda and Seru (2002) noted that training programs can be facilitated by a combination of development agencies with voluntary organizations and other institutions 
of higher education. In this regard, women would be able to acquire skills and readily apply them to their projects. Gradually, this is what is needed to contribute to the alleviation of gender disparities, economic exploitation, and to the economic empowerment of women in Western Kenya. Also, such programs that are close to where women's groups operate, with attention paid to their daily schedules and lives, could serve as a motivation or "incentive" for them to attend rural education and training initiatives that are sensitive to their needs.

"Entrepreneurial, management, and technical training is very important to enterprise development" (Stevenson \& St-Onge, 2005, p. 42). There are many governmental, private, and non-governmental agencies professing to offer training in areas such as starting a business, continuing its existence, and expanding it, yet very few entrepreneurs have access to such training. Additionally, micro-enterprises owned by women still can not access this type of training which they need for the expansion of their enterprises (Stevenson \& St-Onge). From a study conducted in Kenya by the International Labor Organization (ILO), women involved in entrepreneurship reported that the existing infrastructure for training and consultancy was deficient of quality, had no provisions in the rural areas, and even lacked follow-up for the trainees to implement their training. Additionally, this kind of training placed “. . insufficient emphasis on the entrepreneurship, marketing, and business aspects in technical training programs" (Stevenson \& St-Onge, p. 43).

This is in concert with the argument of Waters and Haskell (1988) that the reason for conducting a needs assessment is driven by the ". . . desire to design and implement relevant educational programs which are based on measurable and achievable goals and 
objectives" (p. 26). Moreover, Waters and Haskell contended that the ability to implement appropriate educational programs is contingent upon acquisition of data from “... potential clientele and actively involving them in the process of identifying potential educational programs; thus, increasing the likelihood of achieving appropriate outcomes" (p. 26).

\subsubsection{Theoretical Framework}

The theoretical base for this study is derived from the theory of self-efficacy as postulated by Bandura (1995). "Perceived self-efficacy refers to beliefs in one's capabilities to organize and execute the courses of action required to manage prospective situations. Efficacy beliefs influence how people think, feel, motivate themselves, and act" (p. 2). Self-efficacy further influences our choices, efforts, and determination as we confront the obstacles we face in life. Among the factors influencing the sources of selfefficacy is culture which has an effect on the type of information source, information selected, weighted, and incorporated into people's self-efficacy judgments (Oettingen, 1995).

In this study, women have strong belief in the need to change their destiny. This is exemplified by the type of efforts and strategies they are making in order to enhance their livelihoods in an environment with poor incomes. Women have to contend with the issues of gender bias and economic constraints which make them vulnerable economically, socially, and politically (Buvinic, 1997). As Kiteme (1992) pointed out, women in rural areas have assumed the leadership of their households; a position in which they have to struggle to fulfill its numerous demands. With strong beliefs in their personal abilities and chances of success, women devise strategies to help them meet 
their demands; this entails the formation of women's self-help groups (Mbugua-Murithi, 1997).

Culture also influences these types of associations and their operations. As Oettingen (1995) posited, “. . . culture reveals its effects on self-efficacy beliefs by affecting the fundamental systems and institutions of virtually all human societies: the family, the school, the workplace, and the community" (p. 151).

The beliefs held by women's groups to improve their life conditions are manifested in the choice of welfare and income-generating activities. Feldman (1983), Mbugua-Murithi (1997), and Srujana (1996) asserted that women's groups' activities are aimed at equipping them with the means to acquiring social, educational, and economic empowerment.

Oettingen (1995) uses the theory of self-efficacy to explain how change can take place in societies, especially in societies that are collectivist. This is true of traditional Kenyan rural societies where women help each other in times of needs such as death, sickness, or with the provision of farm labor (Karani, 1987; Srujana, 1996; Thomas 1988).

Performance experience is an important source of building self-efficacy. Success strengthens self-efficacy whereas failure abates self-efficacy (Bandura, 1995). It is through such initiatives that women's groups have catapulted women's morale in mitigating their economic struggles, hence contributing significantly to individual empowerment and community development.

In order to attain significant development in the community, members of the community need to express their needs while at the same time proposing "home-grown 
solutions" (Noordin et al., 2001, p. 521). When leaders are equipped with skills to lead and manage the group, then the group is poised to handle community development effectively (Noordin et al.). Community organizations have the ability to act as their own instruments of change; this has the potential of bringing communities into closer ties with government institutions or service providers such as micro-credit institutions, researchers and scholars, and other individuals and organizations who may be supportive of development (Noordin et al.). Training programs to support the organization of beliefs, whether held by individuals or groups, can be facilitated by a combination of development agencies collaborating with voluntary organizations or with institutions of higher education (Shibanda \& Seru, 2002).

Bandura's theory also extols the fact that people are more likely to participate in activities in which they believe they can succeed. Self-efficacy promotes the premise that one has the potential to mitigate different situations. This is true of women's groups that engage in activities because of the belief in their abilities to accomplish tasks and overcome challenges with the limited resources at their disposal. Similarly, how people respond to their failure and success is also a factor of self-efficacy. For instance, a high sense of self-efficacy correlates with a higher degree of resilience to problems found in life, but conversely low self-efficacy reciprocates with failure.

The theory identifies factors that affect the success or failure of individuals including their collective actions. Accordingly, the theory supports the broad purpose of this study. The body of literature cited also buttresses this theory, as it helps to describe the problem, perceptions, and strategies women's groups in Western Kenya are employing in order to alleviate their economic hardships. Against this background, the 
study has a conceptual and theoretical framework that describes key factors associated with the problem and its possible amelioration, i.e., the phenomenon of women's selfhelp groups in Western Kenya, their needs, challenges, and aspirations regarding economic conditions, and their perceptions concerning related educational and training needs. 


\section{CHAPTER III}

\section{METHODOLOGY}

\subsubsection{Summary}

The aim of this study was to describe selected characteristics and perceptions held by women who are members of self-help groups in the Shaviringa Location, Vihiga District of Western Kenya. Due to the challenges of providing for their families and themselves in an environment with limited income, these women have resorted to the formation of informal networks (i.e., self-help groups) to mitigate some of their socioeconomic challenges collectively (Buvinic, 1997; Neitzert, 1996; Snow \& Buss, 2001; Thomas, 1987). Their common mode of operation is the establishment of incomegenerating activities that are supported by group members' contributions.

Therefore, this study sought to describe what women, who were members of these associations, perceived to be their needs and how the performance of their associations could be improved. An improvement in their performance as groups could improve their lives. Special emphasis was focused on the educational and training needs of the women's self-help groups and the development of recommendations that could be used to improve the functioning of groups in the Shaviringa Location, Vihiga District of Western Kenya. The researcher conducted semi-structured, focus group interviews (Creswell, 2005; Krueger, 2000; Patton, 1999) of 11 women's self-help groups during May and June 
2007 to answer seven research questions that guided the collection of data. The interview questionnaire consisted of 43 items. Two research assistants worked with the researcher to carry out the interviews. The researcher tabulated and summarized the data.

\section{Purpose of the Study}

The purpose of this study was to describe selected characteristics and perceptions of women who belonged to self-help groups in the Shaviringa Location, Vihiga District of Western Kenya. The women's perceived needs related to improving their livelihoods and economic status were of special interest to the researcher, especially for the purpose of developing recommendations for training and education programs to improve the life conditions of women in rural Kenya. The researcher conducted semi-structured, focus group interviews of 11 women's self-help groups during May and June 2007. Seven research questions were developed to guide the collection of data.

\section{Research Questions}

1. What were selected characteristics of the women's self-help groups and their members?

2. What were selected perceptions of women about the formation, primary activities, and benefits of their self-help groups?

3. What were selected perceptions of women regarding their needs for education and training as it pertained to the acquisition of vocational and business skills by members of their self-help groups?

4. What were selected perceptions of women regarding access to information and use of communication channels by members of their self-help groups? 
5. What were selected perceptions of women concerning the governance, management, and leadership of their self-help groups?

6. What were selected perceptions of women regarding the financial operations of their self-help groups?

7. What were selected perceptions of women regarding other factors that affected the performance of their self-help groups (e.g., marketing of products and services, culturally rooted gender bias, ways of improving their groups, and mobility or transport issues)?

\subsubsection{Introduction and Study Design}

There has been an "increasing consensus among development specialists that poverty is a multidimensional phenomenon that is not adequately captured by measurements of income or expenditure. Broadening the concept of poverty to include vulnerability, social isolation, insecurity, and voicelessness, however, has increased the demand for a broader range of qualitative and quantitative methods, particularly in countries undergoing rapid change ..." (Dudwick, Gomart, Marc, \& Kuehnast, 2003, p. 9).

This was a qualitative case study that used semi-structured, focus group interviews to collect data from its participants. "A key characteristic of qualitative methods is their focus on understanding human behavior in its social, cultural, political, and economic context" (Dudwick et al., 2003, p. 10).

"Multiple data gathering techniques are frequently used in qualitative studies ... so as to develop a more complex understanding of the phenomena being studied" 
(Fossey, Harvey, McDermott, \& Davidson, 2002, p. 727). Fossey et al. (2002) further posited that the "importance for enhancing the quality of data lies in the idea that gathering information from multiple sources (e.g., interviews, observations) will illuminate different facets of situations and experiences and help portray them in their complexity" (p. 727). "Qualitative methods rest on the assumption that reality is socially constructed through ongoing communication and negotiation within communities or groups, and therefore that every member of the community possesses important local knowledge ... social reality and 'local knowledge' are constantly evolving ..." (Dudwick et al., p. 14).

This method can be employed "to understand a research problem" (Creswell, 2005, p. 511). Morgan (1997) stated that, "The hallmark of focus groups is their use of group interaction to produce data and insights that would be less accessible without the interaction found in a group" (p. 2). Morgan further contended that the use of focus groups "give voice" (p. 20) to groups that are marginalized and which would not otherwise be heard, such as "single mothers" with "low income" (p. 20).

The selection of the research site and women's groups involved in this study were chosen based on what Creswell (2005), Dudwick et al. (2003), and Merriam (1998) described as a purposeful sample. Purposeful sampling enables researchers to "intentionally select individuals and sites to learn and understand the central phenomenon" (Creswell, p. 204) in order "to gain a deeper understanding of the situation and meaning for those involved" (Merriam, p. 19). The power of value of the case study approach lies in the process and its discovery rather than solely outcomes and confirmation. Case studies provide insights that could have valuable influence on "policy, 
practice, and future research" (Merriam, p. 19). "Designing local or regional policies, for example, generally requires greater understanding of local values and expectations and social norms and networks, all of which qualitative methods are designed to elicit" (Dudwick et al., p. 11). By focusing on a single case, the investigator is able to expose the interaction of aspects attributable to the occurrence.

Merriam posits that case studies "concentrate attention on the way particular groups of people confront specific problems, taking holistic view of the situation" by virtue of being "problem-centered, small-scale endeavors" (p. 29). If a researcher is interested in information regarding a certain population or area, a descriptive study suffices. There are multiple strengths in the application of a case study. For instance, case studies are ideal when investigating social units that are complex and have inherent variables which are crucial in comprehending a phenomenon. Also, when applied to reallife situations, case studies yield "a rich and holistic account of the phenomenon" (Merriam, 1998, p. 41). Case studies have also proved to be "useful for studying educational innovations, for evaluating programs, and for informing policy” (p. 41).

Krueger (2000) argued that focus groups enable a researcher to generate more information about opinions or attitudes across several groups of people. And, that findings from focus groups are vital for understanding as well as making well-informed decisions on development matters by those at the policy or decision-making level (Krueger). Focus groups are also important when doing needs assessments for programs (Krueger). "The group's dynamics typically contribute to focusing on the most important topics and issues in the program, and it is fairly easy to assess the extent to which there is 
a relatively consistent, shared view of the program among participants" (Patton, 1990, p. 336).

Focus groups are also ideal in identifying “... strengths, weaknesses, and needed improvements" (p. 336); thus, the usage of focus groups has been applied in a “. . full range of evaluation purposes" (p. 336). Apart from knowledge accumulation, groups also "give rise synergistically to insights and solutions that would not come about without them" (Patton, p.17). "Focus groups, which often group people according to an important social characteristic presumed to shape their views (such as sex, age, educational level, or education), are useful for rapidly assessing and characterizing group-specific interests, needs, and concerns. Focus group discussions can reveal the parameters of an issue and raise new concerns . . . the very process of dispute and negotiation during discussions provides information about how much diversity exists (or is tolerated) within a given social group or community" (Dudwick et al., p. 16).

The study’s design adapted a "phenomenological inquiry” approach (p. 69), i.e., one that focuses on the "structure and essence of experience of this phenomenon for these people" (p. 69). Patton argued that a phenomenon being experienced could be an emotion, a relationship, a marriage, a program, an organization, or even a culture. Another dimension to a phenomenological approach is "the assumption that there is an essence or essences to shared experiences ... These essences are the core meanings mutually understood through a phenomenon commonly experienced" (p. 70). The participants in a focus group "are usually selected because of shared social or cultural experiences (e.g., gender, ethnicity)" (Fossey et al., 2002, p. 727). Also, the use of focus 
groups has been effective with groups that are marginalized and are willing to talk to people with similar experiences (Fossey et al.).

\subsubsection{Institutional Review Board}

Federal regulations and Oklahoma State University policy require review and approval of all research studies that involve human subjects. The office of the University Research and the Institutional Review Board at Oklahoma State University conducted the aforementioned review to protect the rights and welfare of human subjects involved in biomedical human research. In compliance with this policy, this study received the proper surveillance and was granted permission to be executed. The institutional review board code for this study was GU075 and a copy of the approval form is presented in Appendix A.

\subsubsection{Data Collection Instrument}

To gather specific information from the women's groups, a questionnaire was used to collect information from the participants (Merriam, 1998). The items asked were fashioned around several broad categories of questions to which the groups' members responded: education levels attained; ages of groups' members; purposes and functions of the groups; business experiences; sources of group conflicts; perceptions about marketing; organization and management; savings and credit approaches; sources of information and communication; views about trade schools; training and education needs. A total of 43 questions were asked: four closed, 34 semi-closed, and five open-ended (see 
Appendix B). In all, 11 interview meetings were held that included 64 women who were members of 11 different women's groups.

\subsubsection{Research Assistants}

The study employed the services of two research assistants who are trained instructors at a local Government of Kenya Institute of Research and Technology. They also had previous research experience in entrepreneurship studies. Before commencing the study, both research assistants were contacted via telephone by the researcher and sensitized about research ethics and procedures with human subjects. A face-to-face session took place with the researcher in Kenya in May 2007 to further inform the research assistants about the ethical requirements of the study and its procedures.

\subsubsection{Pilot Study}

In March 2007, a pilot semi-structured, interview questionnaire developed by the researcher was sent to a research assistant at the study site via electronic mail. It was administered to one women's group and the results were returned to the researcher. Comments from the pilot group and research assistant were then used to refine and improve the questionnaire. Data from the pilot group were not included in the study's final results.

\subsubsection{Role of Community Leaders}

The participating women's groups were solicited with the recommendation of local community leaders, i.e., Location Chief and Sublocation Deputy Chief in their 
respective areas of jurisdiction in Shaviringa Location, Tiriki East Division, Vihiga

District of Western Kenya. It was believed that the Chief of Shaviringa Location and her Deputy Chief were appropriate officials (i.e., knowledgeable and reliable) to inform the researcher about appropriate women's self-help groups to interview for purpose of the study. Local community leaders identified a total of 12 women's groups based on their size of membership and level of activity.

\subsubsection{Sample Description}

The interview sample included only female participants who belonged to the 11 self-help groups identified. No overt recruitment techniques or incentives were used. In most cases, interviews were conducted during regular group activity or meeting times. In special circumstances, when it was difficult to schedule an interview, special meeting times were arranged at locations convenient for the participants. Participants volunteered to participate in the study based on their choice to attend designated group meetings or activities. In a few cases, interviews were conducted at a workplace or at a group leader's home. All interviews were between one and two hours in length (Patton, 2002).

\subsubsection{Data Collection}

In June 2007, data were collected from 11 groups of women using the semistructured, interview questionnaire procedure (Creswell, 2005). For nine groups, the range of interview participants was 5 to 7 women. Krueger (1999) stated that focus

groups are normally in the range of "6 to 9 participants," although " 4 to 6 participants are 
becoming increasingly popular because the smaller groups are easier to recruit and host and more comfortable for participants" (p. 79). The members' responses were combined and summarized to create a "consensus" that described the group's overall opinions and perceptions. Two other groups had designated spokespersons who responded to the questions on behalf of their groups' members.

\subsubsection{Languages Used During the Interviews}

English, Swahili (Kenyan's national language), vernacular (Tiriki dialect of the Luhya ethnic tribe widely spoken in Western Kenya), and a mixture of all three languages were used in collecting the information from members of eight groups. However, in the case of three groups, the questionnaire had to be translated into Tiriki dialect and interpreted for the participants.

\subsubsection{Data Analysis Procedures}

The results of the 11 interviews were reviewed and summarized by the researcher, i.e., hand tabulation with the aid of a calculator. Frequency counts of the groups' responses to the closed (4) and semi-closed (34) questions were calculated as well as corresponding percentages. In the case of the semi-closed questions, i.e., where "other" and similar opportunities for elaboration were offered, the responses were also summarized to be presented as findings. The groups' responses to the questionnaire's open-ended items (5) were reviewed by the researcher and presented intact as direct quotes where said statements supported answering the study's research questions. An 
overall portrait of participant's responses was constructed and used to describe findings, draw conclusions, and develop recommendations for future practice and research.

\subsubsection{Challenges Encountered}

During the collection of data, various challenges were encountered that shaped this study. Very few respondents per group turned up for interviews because of household duties like cooking or taking care of the homestead in the absence of their husbands. In some cases, groups' members were too sick to attend an interview, while other group members were attending to their businesses at either village markets or roadsides. For some, participating in the interviews involved walking long distances to a designated group leader's home; so, long distances affected groups' members' attendance at scheduled meetings. The weather during the time of data collection was wet due to heavy rains in the months of May and June; this also affected the distance participants could travel and their timeliness to the interview meetings.

Many of the groups' members were also tied to their farm duties or needed to cook for their families and could not attend the interviews. Some groups' members demanded a monetary incentive for their time to attend the interview sessions if they were required to walk long distances. In these instances, the principal investigator together with the research assistants walked to the groups' meeting places (e.g., an average of $10 \mathrm{~km}$ between meeting places). The distance traveled (by foot) was immense because the women's groups were widely distributed in the Shaviringa Location. 


\section{CHAPTER IV}

\section{RESULTS/FINDINGS}

\subsubsection{Summary}

The aim of this study was to describe selected characteristics and perceptions held by women who are members of self-help groups in the Shaviringa Location, Vihiga District of Western Kenya. Due to the challenges of providing for their families and themselves in an environment with limited income, these women have resorted to the formation of informal networks (i.e., self-help groups) to mitigate some of their socioeconomic challenges collectively (Buvinic, 1997; Neitzert, 1996; Snow \& Buss, 2001; Thomas, 1987). Their common mode of operation is the establishment of incomegenerating activities that are supported by group members' contributions.

Therefore, this study sought to describe what women, who were members of these associations, perceived to be their needs and how the performance of their associations could be improved. An improvement in their performance as groups could improve their lives. Special emphasis was focused on the educational and training needs of the women's self-help groups and the development of recommendations that could be used to improve the functioning of groups in the Shaviringa Location, Vihiga District of Western Kenya. The researcher conducted semi-structured, focus group interviews (Creswell, 2005; Krueger, 2000; Patton, 1999) of 11 women's self-help groups during May and June 
2007 to answer seven research questions that guided the collection of data. The interview questionnaire consisted of 43 items. Two research assistants worked with the researcher to carry out the interviews. The researcher tabulated and summarized the data.

\section{Purpose of the Study}

The purpose of this study was to describe selected characteristics and perceptions of women who belonged to self-help groups in the Shaviringa Location, Vihiga District of Western Kenya. The women's perceived needs related to improving their livelihoods and economic status were of special interest to the researcher, especially for the purpose of developing recommendations for training and education programs to improve the life conditions of women in rural Kenya. The researcher conducted semi-structured, focus group interviews of 11 women's self-help groups during May and June 2007. Seven research questions were developed to guide the collection of data.

\section{Research Questions}

1. What were selected characteristics of the women's self-help groups and their members?

2. What were selected perceptions of women about the formation, primary activities, and benefits of their self-help groups?

3. What were selected perceptions of women regarding their needs for education and training as it pertained to the acquisition of vocational and business skills by members of their self-help groups?

4. What were selected perceptions of women regarding access to information and use of communication channels by members of their self-help groups? 
5. What were selected perceptions of women concerning the governance, management, and leadership of their self-help groups?

6. What were selected perceptions of women regarding the financial operations of their self-help groups?

7. What were selected perceptions of women regarding other factors that affected the performance of their self-help groups (e.g., marketing of products and services, culturally rooted gender bias, ways of improving their groups, and mobility or transport issues)?

\subsubsection{Selected Characteristics of the Women's Self-Help Groups and Their Members in the Shaviringa Location, Vihiga District of Western Kenya}

Eleven women's self-help groups were studied in total. Members of the groups had different levels of education. Five (45.5\%) groups had members who possessed "mixed levels" of education that ranged from primary, high school, college, and university (see Table 2). Three (27.3\%) groups had members who had varying levels of primary school education or who had acquired some level of vocational training. Three (27.3\%) groups included members who had attained high school educations but nothing in addition to that (see Table 2).

Regarding years of operation, six (54.5\%) groups had less than five years of operation; two (18.2\%) groups had between five and ten years; and, three (27.3\%) groups had been in operation for more than 10 years (see Table 2).

The groups also had varied membership sizes. Two (18.2\%) groups had 10 to 19 members; five (45.5\%) groups had 20 to 29 members; one (9.1\%) group had 30 to 39 
members; two (18.2\%) groups had 40 to 49 members; and, one (9.1\%) group had 50 to 59 members (see Table 2). Group size influenced the number of times groups met for activities and projects, i.e., whether on a weekly or monthly basis. Groups with a membership of 10 to 19 met once a month (18.3\%); those with 20 to 29 and 30 to 39 members met twice (27.3\%) a month; and, groups with 40 or more members met on a weekly (54.2\%) basis or as "needs arose" (see Table 2). Regarding groups' meeting locations, eight (72.7\%) groups operated from their members' homes on a rotational basis; two (18\%) groups operated from a church premise; and, one (9.1\%) group used either an "open-air" field, a school, or a rented a space (see Table 2).

Nine (81.8\%) groups included members who were aged 60 to 69 ; seven (63.6\%) groups had some members who were aged 50 to 59; six (54.5\%) groups included some members who were aged 40 to 49 and 70 to 79 ; four (36.4\%) groups had members whose ages ranged from 30 to 39 years; and, two (18.2\%) groups included members who were 20 to 29 as well as 80 to 89 years of age (see Figure 2). 
Table 2

Selected Characteristics of Women's Self-Help Groups and Their Members in the Shaviringa Location, Vihiga District of Western Kenya

f $\%$

\section{Levels of Education}

Mixed: Primary school, High School, College, \& University

45.5

Primary school and/or Vocational Training

5
3 $\quad 27.3$

High School

$3 \quad 27.3$

\section{Years of Operation}

Less than 5 years

Between 5 and 10 years

More than 10 years

$3 \quad 27.3$

Group's Membership Sizes

10 to 19 members

20 to 29 members

$2 \quad 18.2$

30 to 39 members

$5 \quad 45.5$

40 to 49 members

19.1

50 to 59 members

$2 \quad 18.2$

19.1

Number of Times Groups Meet

Once a month

Twice a month

$6 \quad 54.5$

Weekly (more frequently "as needs arise")

$3 \quad 27.3$

Groups' Meeting Places

Members' homes (Rotational)

$8 \quad 72.7 \%$

Church

$2 \quad 18.2 \%$

"Open-air" field, school, or a rented space

$1 \quad 9.1 \%$




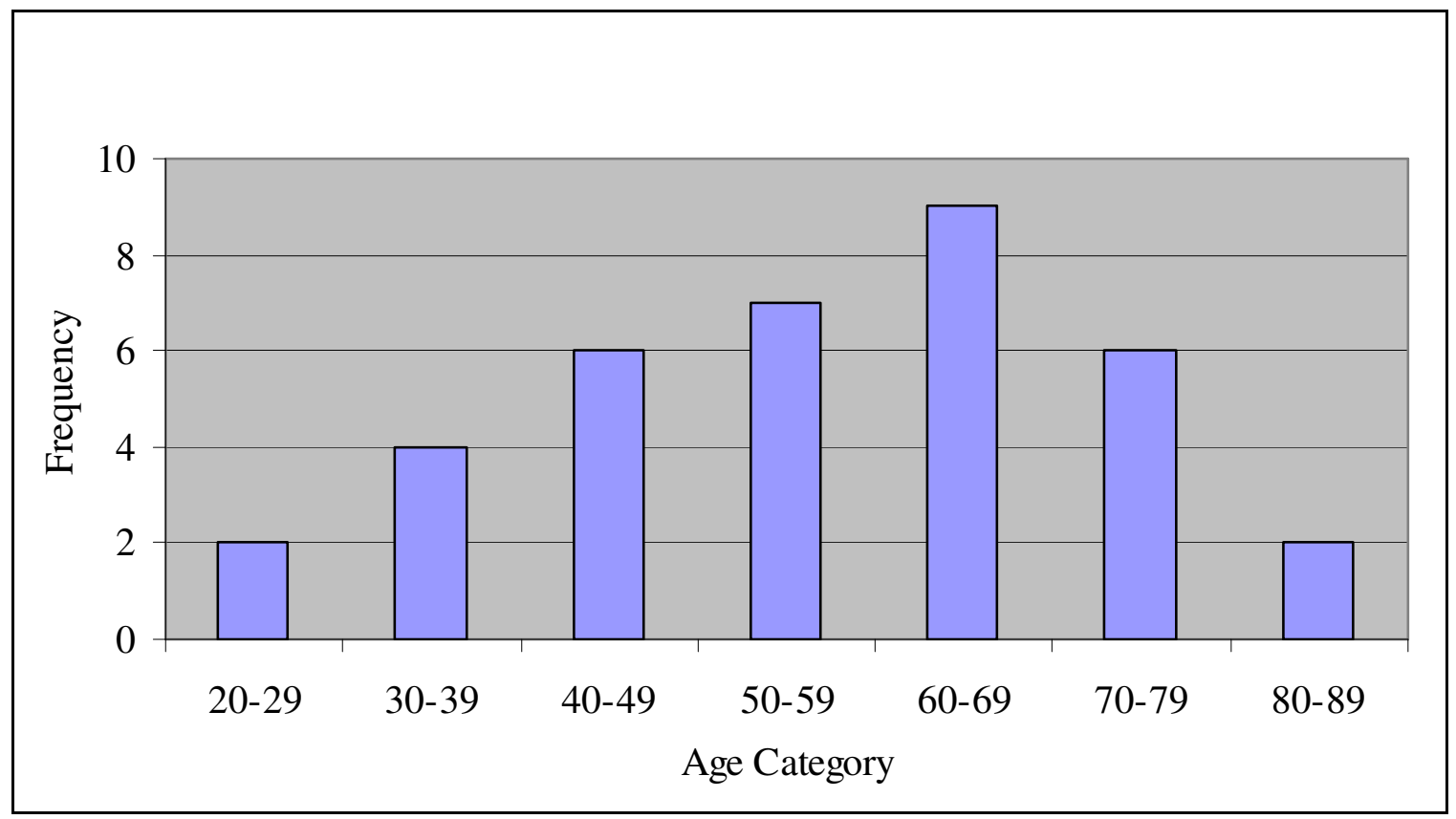

Figure 2: Age Categories of Members of Women's Self-Help Groups in the Shaviringa Location, Vihiga District of Western Kenya.

\subsubsection{Selected Perceptions of Women about the Formation, Primary Activities, and Benefits of Their Self-Help Groups in the Shaviringa Location, Vihiga District of Western Kenya}

Various reasons or purposes were given for the formation of the self-help groups. Eight $(72.7 \%)$ groups were formed for the purpose of assisting orphans; six $(54.5 \%)$ groups hoped to acquire household items; four (36.4\%) groups were affiliations of widows; two (18.2\%) groups wished to establish nursery schools (i.e., early childhood education); one $(9.1 \%)$ group was focused on entertainment; and, one group $(9.1 \%)$ collected and sold firewood (see Table 3).

In terms of primary activities, all groups were involved in a rotating-credit scheme (Sindikiza); four (36.4\%) groups practiced "Table Banking”; four (36.4\%) groups practiced subsistence agriculture (for home consumption only) (see Table 3). Groups also 
produced food products for their members' use and for sale; two (18.2\%) groups kept poultry; two (18.2\%) groups reared livestock; two (18.2\%) groups were involved in the sale of grains, cereals, and vegetables; and, one (9.1\%) group had a bee-keeping project for the sale of honey. Two (18.2\%) groups were involved in early childhood education programs; two (18.2\%) groups were involved in brick-making; one (9.1\%) group sold firewood; and, one (9.1\%) group tailored clothes (see Table 3).

The women's groups indicated that there were benefits which accrued out of being members of their associations. Nine (81.8\%) groups stated that they had acquired extra income and members were able to access "easy loans" from their groups" collective economic enterprises (see Table 3). Seven (63.6\%) groups had acquired household items, and five (45.5\%) groups' members had been able to improve their houses, e.g., the purchase of household items. Three (27.3\%) groups bought livestock; three (27.3\%) groups were able to provide support to others during funerals of close family members; and, two (18.2\%) groups established nursery schools for young children. Members of one (9.1\%) group had managed to construct permanent water tanks near their homes to solve water accessibility problems (see Table 3). 
Table 3

Selected Perceptions of Women about the Formation, Primary Activities, and Benefits of Their Self-Help Groups in the Shaviringa Location, Vihiga District of Western Kenya

$f$

\section{Stated Reasons for Forming Women's Self-Help Groups*}

Assist orphans

Acquire household items

Assist widows

6

Create a nursery school (i.e., early childhood education)

4

Provide entertainment services

2

18.2

Collecting and selling firewood

\section{Primary Activities*}

Rotating credit (Sindikiza)

100

Table banking

$\begin{array}{cc}11 & 100 \\ 4 & 36.4 \\ 4 & 36.4 \\ 2 & 18.2 \\ 2 & 18.2 \\ 2 & 18.2 \\ 2 & 18.2 \\ 2 & 18.2 \\ 1 & 9.1 \\ 1 & 9.1 \\ 1 & 9.1\end{array}$

\section{Perceived Benefits*}

Developed alternative sources of income 9

$\begin{array}{ll}\text { Acquired household items } & 7\end{array}$

*Note. In the case of this question, groups indicated more than one answer. 


\subsubsection{Selected Perceptions of Women Regarding Their Needs for Education and Training as it Pertained to the Acquisition of Vocational and Business Skills by Members of Their Self-Help Groups in the Shaviringa Location, Vihiga District of Western Kenya}

Generally, a consensus existed among all the groups studied on the need for a trade school in their areas of operation. The groups further stated that a trade school would enable them to improve their skills, generate new ideas, increase their performance, and also diversify their sources of income. One group perceived that a trade school would also "absorb the school drop outs, promote the exchange of skills between groups, and, overall, help recycle community funds that people pay to schools in urban areas around the country [i.e., mitigate the loss of rural resources to urban centers]."

If a trade school was constructed, $10(90.9 \%)$ groups preferred that it be built near a shopping center within their villages (see Table 4). Their rationale was that such a location for a trade school would save them from walking long distances to a school at the expense of time needed to attend to group activities or household duties. However, one $(9.1 \%)$ group had no preference regarding the site for such a school (see Table 4).

The researcher also sought to learn whom the groups' members preferred to attend education and training opportunities. The groups expressed the hope that that all members could attend skills training. However, one (9.1\%) group preferred that its younger members attend trainings because it was perceived that those individuals had fewer household commitments and possessed greater abilities to grasp new skills and information. Although all the groups preferred that women attend the proposed trainings, one $(9.1 \%)$ group recommended that men also attend such training opportunities (see Table 4). The latter group's rationale was that, "Men are able to grasp some skills faster 
than women. By so doing, they would be incorporated in the groups so as to diversify skills and sources of income. Also, this training could be extended to our unemployed children."

Regarding the mode of training (i.e., instructional delivery), all the groups preferred "hands-on" instruction. In addition, three (27.3\%) groups preferred training sessions with a facilitator; and, three $(27.3 \%)$ groups expressed preference for hands-on training sessions to include group discussions that would be participatory in nature (see Table 4). The groups also expressed interests in the type of topics they preferred be included in the education and training sessions. All groups preferred agriculture, business, and some health (i.e., AIDS) education for the sake of those providing homecare services to relatives and friends who were ill. One of the (9.1\%) groups also expressed interest in being educated on political issues, and another group (9.1\%) supported the establishment of rural adult literacy programs for older women who had never received any education or training previously (see Table 4).

Ten $(90.9 \%)$ groups supported the establishment of a mobile training unit (MTU) (see Table 4). Those groups noted that a mobile training unit could easily access many women, reach more women's groups, cover greater geographical distances, provide information readily to women, and save them from walking long distances. One group expressed that,

A mobile training unit is a very practical idea. Women always want to be near their homes as they train, and a mobile training unit would reach many women's groups over a wide distance, help in enhancing group recruitment, promote 
exchange of experiences among groups, and enable women to make new discoveries.

However, one (9.1\%) group differed on the need for a mobile training unit by observing that the use of a mobile training unit would be unreliable and it would require long periods of time to acquire a skill. That group preferred the establishment of a community training center or a trade school instead (see Table 4). 
Table 4

Women's Self-Help Groups' Perceptions of Their Education and Training Needs in the Shaviringa Location, Vihiga District of Western Kenya

f $\%$

\section{Prefer Trade School}

Yes

11

100

No

0

0

Preferred Location

Shopping center in the village

10

90.9

No preference

9.1

Training Sessions Attendance*

All Members

11

100

Younger groups' members

All members and men

$1 \quad 9.1$

$1 \quad 9.1$

Preferred Mode of Training/Learning*

"Hands-on" instruction

11

100

Facilitator-led instruction

3

Discussions and participatory activities

3

27.3

27.3

Preferred Training/Education Topics*

Agriculture, business, health

11

90.9

Politics

1

Adult literacy program

1

9.1

9.1

Mobile Training Unit

Yes

10

90.9

No

1

9.1

Note. In the case of this question, some groups indicated more than one answer.

\subsubsection{Selected Perceptions of Women Regarding Access to Information and Use of Communication Channels by Members of Their Self-Help Groups in the Shaviringa Location, Vihiga District of Western Kenya}

The researcher also wanted to identify the existing sources of information and communication channels used by the groups. All the groups reported that they relied on 
word of mouth, local village meetings (i.e., Baraza in Swahili), attending funerals, and radio broadcasts as their primary sources of information (see Table 5). Most groups also reported that through collective economic activities, some women had acquired inexpensive television sets operated by $12 \mathrm{~V}$ auto batteries. Also, the general observation among all the groups was that market centers, village shops, funeral ceremonies, church functions, village opinion leaders (Rogers, 2003), cultural ceremonies, and village development committees formed viable interpersonal communication networks (Rogers) on which they relied (see Table 5). Rogers noted that "different communication channels played different roles at each stage in the innovation decision process" (p. 204). And, it is these differences that help in "persuading individuals to change their attitude toward an innovation [e.g., a new practice or way of doing something]" (p. 205). Rogers further observed that opinion leaders are crucial because of "serving as an avenue for the entrance of new ideas to their system" (p. 317).

Groups whose members were able to read and write composed handwritten letters to communicate among themselves about group activities. Within a group, members were designated to handle communication and convey messages to other participants. 
Table 5:

Existing Sources of Information and Communication Channels as Expressed by Women's Self-Help Groups in the Shaviringa Location, Vihiga District of Western Kenya

Sources/Channels

Church functions

Cultural ceremonies

Funeral attendance

Local village meetings (Baraza)

Market centers

Radio broadcasts

Village development committees

Village opinion leaders

Village shops

Word of mouth

\subsubsection{Selected Perceptions of Women Concerning the Governance, Management, and Leadership of Their Self-Help Groups in the Shaviringa Location, Vihiga District of Western Kenya}

Various factors affecting the general governance, management, and leadership of the women's groups were identified: registration status of the group; selection of group leaders; sources of conflicts; and, from where a group operated (physical location). Ten (90.9\%) groups were registered with the Government of Kenya's Ministry of Culture and Social Services (see Table 6). This was due to a requirement by the government or bank institutions that to open a bank account and acquire a loan, a group must be registered. Also, most of the groups believed that they needed to be registered to operate freely and attract external assistance. Only one (9.1\%) group was not registered; its members disagreed on the need for such a status (see Table 6).

Rationale and procedures for selecting leaders varied between groups. When choosing leaders, eight (72.7\%) groups relied on their perceptions of trust, education, and 
participation (see Table 6). Three (27.3\%) groups focused on integrity, influence, and experience to select their leaders. Nine $(81.8 \%)$ groups elected their leaders by a majority of votes cast. However, two (18.2\%) groups "nominated" their leaders, i.e., a member would be nominated to serve, no other individual's name would be offered, and, thus, the single nominee would be “elected." For seven (63.6\%) groups, tardiness, using domestic issues as a rationale for tardiness, absenteeism, or slow repayment of loans were responsible for conflicts among group members. In four (36.4\%) groups, the sources of conflicts were mainly about leadership, accountability, and transparency (see Table 6).

Table 6

Factors Affecting Governance, Management and, Leadership of Women's Self-Help Groups in Shaviringa Location, Vihiga District of Western Kenya

\begin{tabular}{ccc}
\hline$f$ & $\%$ \\
\hline
\end{tabular}

\section{Registration Status}

Legally registered

Not registered

$\begin{array}{cc}10 & 90.9 \\ 1 & 9.1\end{array}$

\section{Rationale and Procedures for Selecting Leaders}

Trust, education, and/or participation

Integrity, influence, and/or experience

Methods of Selecting Leaders

Election by majority vote

Selection without a vote ("nomination")

Perceived Sources of Conflicts

Tardiness, using domestic issues as an excuse, absenteeism, or slow loan repayment Leadership, accountability, transparency
8

3

72.7

27.3

9
21.8

$2 \quad 18.2$

$4 \quad 36.4$ 


\subsubsection{Selected Perceptions of Women Regarding the Financial Operations of Their Self-Help Groups in the Shaviringa Location, Vihiga District of Western Kenya}

Only three (27.3\%) groups had opened bank accounts (see Table 7). Eight (72.7\%) groups did not have bank accounts due to lack of sufficient capital, and because the fees required by banks to open and maintain accounts were viewed as prohibitive. In addition, in most cases, the groups' incomes had been loaned to their members, so little cash remained to be "saved." Many of the groups kept some form of records of meetings, contributions, and projects, or for accountability purposes and future reference.

All of the groups admitted to having minimal business experience. Many of the groups' members interviewed stated that they joined their groups without any experience in business but acquired some limited business skills after raising capital to start businesses supported by their respective associations (see Table 7). All the groups expressed a desire to receive external assistance (e.g., seed capital). If provided, their priorities would be the purchase of materials or equipment for operation and expansion of their income-generating activities. And, some of the groups indicated they would construct better houses or start some form of training program(s). 
Table 7

Factors Influencing Financial Operations of Women's Self-Help Groups in the Shaviringa Location, Vihiga District of Western Kenya

\%

\section{Holds a Bank Account}

No

Yes

8

3

72.7

27.3

Kept Records of Any Kind

Yes

No

11

100

1

0

\section{Business Experience}

Minimal

\subsubsection{Selected Perceptions of Women Regarding Other Factors That Affected the Performance of Their Self-Help Groups in the Shaviringa Location, Vihiga District of Western Kenya}

The groups were also asked about other factors that affected the efficient functioning of their associations. The factors expressed included issues related to marketing, transport of goods produced, potential limitations, motivations as well as suggestions related to improving their operating environments. Ten (90.9\%) groups reported that their marketing abilities were hampered by poor prices, poor local demand, competition with experienced groups and other general traders, and the inability to access large urban markets (see Table 8). Only one (9.1\%) group perceived that marketing was not an issue. However, that group was not involved in any business ventures.

All the groups in the study depended on local means of transport such as bicycles, taxi services, and, in most cases, walking to get their products to the local markets.

Groups' members stated that walking long distances to the market or to attend group 
functions was an impediment to their productivity given their advancing age and household duties. Whenever the weather was rainy many group members faced additional hardships because of even more lost time. One group that sold firewood decried the lack of means to transport their bulky products to the market. So, they fell prey to exploitation by transporters, who, in most cases, were expensive; this, in turn, impacted the group's profitability. Another group that engaged in the provision of entertainment activities such as song, drama, and dance did not have the means to travel long distances and perform despite demand for its services. A different group noted the following:

We live far in the interior where we are isolated from the market center. Whenever we purchase foodstuff for our feeding program at our early childhood facility we are also forced to pay for bicycle transport for ourselves and our purchases too. At our age, bicycle transport is not so good so walking becomes the only alternative. Some members abstain from such responsibilities and this becomes a recipe for conflicts in our group.

Eight (72.7\%) groups indicated that culturally rooted gender bias was another setback to their operations (see Table 8). The women reported that local cultural tenets continue to stereotype the abilities of women in regard to certain vocations. For example, one group reported that, "In our culture, women cannot plant trees or lead a prayer during public functions like burial ceremonies. Women are best suited as mothers or casual labors."

Some of the groups observed that their main limitations were lack of education and new ideas to improve existing activities rather than duplicating projects carried out 
by other groups in their areas. Seven (63.6\%) groups suggested that education and training through seminars and workshops by external actors, group-provided demonstrations and local shows, as well as support from the Kenyan government and NGOs would improve the performance of women's self-help groups (see Table 8). The women's groups studied also expressed that they deserved to be recognized and appreciated for their roles in community development. All the groups expressed interest in receiving "appropriate rewards" such as certificates for their contribution to the community. To that end, one group expressed the following position:

“We need a community center and a local women's group day to reward different groups and learn from others. Rewards would easily encourage more women to join these initiatives. Sindikiza has improved women's lives significantly; so, the demand has increased and many more would like to join to improve their lives too." 
Table 8:

Other Factors Affecting Women's Self-Help Groups Regarding Their General

Performance in the Shaviringa Location, Vihiga District of Western Kenya

\% $\%$

\section{Markets \& Marketing of Products}

Poor prices, poor local demand, competition with experienced groups or traders, inadequate capital, and/or the inability to access large urban markets No business involvement

$1 \quad 9.1$

\section{Culture and Gender Bias}

Yes

Not indicated

\section{Ways of Improving Group Performance}

Seminars and workshops by external actors

Group-provided demonstrations and local shows

More support from the Kenyan government

No other factors identified

$4 \quad 36.4$




\section{CHAPTER V}

\section{SUMMARY AND CONCLUSIONS}

\subsubsection{Summary}

The aim of this study was to describe selected characteristics and perceptions held by women who are members of self-help groups in the Shaviringa Location, Vihiga District of Western Kenya. Due to the challenges of providing for their families and themselves in an environment with limited income, these women have resorted to the formation of informal networks (i.e., self-help groups) to mitigate some of their socioeconomic challenges collectively (Buvinic, 1997; Neitzert, 1996; Snow \& Buss, 2001; Thomas, 1987). Their common mode of operation is the establishment of incomegenerating activities that are supported by group members' contributions.

Therefore, this study sought to describe what women, who were members of these associations, perceived to be their needs and how the performance of their associations could be improved. An improvement in their performance as groups could improve their lives. Special emphasis was focused on the educational and training needs of the women's self-help groups and the development of recommendations that could be used to improve the functioning of groups in the Shaviringa Location, Vihiga District of Western Kenya. The researcher conducted semi-structured, focus group interviews (Creswell, 2005; Krueger, 2000; Patton, 1999) of 11 women's self-help groups during May and June 
2007 to answer seven research questions that guided the collection of data. The interview questionnaire consisted of 43 items. Two research assistants worked with the researcher to carry out the interviews. The researcher tabulated and summarized the data.

\section{Purpose of the Study}

The purpose of this study was to describe selected characteristics and perceptions of women who belonged to self-help groups in the Shaviringa Location, Vihiga District of Western Kenya. The women's perceived needs related to improving their livelihoods and economic status were of special interest to the researcher, especially for the purpose of developing recommendations for training and education programs to improve the life conditions of women in rural Kenya. The researcher conducted semi-structured, focus group interviews of 11 women's self-help groups during May and June 2007. Seven research questions were developed to guide the collection of data.

\section{Research Questions}

1. What were selected characteristics of the women's self-help groups and their members?

2. What were selected perceptions of women about the formation, primary activities, and benefits of their self-help groups?

3. What were selected perceptions of women regarding their needs for education and training as it pertained to the acquisition of vocational and business skills by members of their self-help groups?

4. What were selected perceptions of women regarding access to information and use of communication channels by members of their self-help groups? 
5. What were selected perceptions of women concerning the governance, management, and leadership of their self-help groups?

6. What were selected perceptions of women regarding the financial operations of their self-help groups?

7. What were selected perceptions of women regarding other factors that affected the performance of their self-help groups (e.g., marketing of products and services, culturally rooted gender bias, ways of improving their groups, and mobility or transport issues)?

\subsubsection{Selected Characteristics of the Women's Self-Help Groups and Their Members in the Shaviringa Location, Vihiga District of Western Kenya}

In total, 11 groups were interviewed regarding their levels of education, years of operation, membership sizes, the number of times they met, meeting locations, and the age categories of their members. Most groups had mixed levels of education that ranged from some primary, vocational, high school, college, and university education.

Six groups had been in operation for less than five years; the other five groups had operated for more than five years. Group sizes ranged from 10 to 19 members to as large as 50 to 59; a group size of 20 to 29 was most common. Most groups met either once or twice a month, depending on the size of the group. Most of the groups operated from their members' homes where they met on a rotational basis. Group members' ages ranged from as young as 20 to 29 years to as old as 80 to 89 years. It was more likely that the predominance of groups' members were age 60 and older (see Figure 2). 
5.2.0 Selected Perceptions of Women about the Formation, Primary Activities, and Benefits of Their Self-Help Groups in the Shaviringa Location, Vihiga District of Western Kenya

Groups were formed to assist HIV-AIDS orphans and widows, acquire household items, or for entertainment purposes. Groups' primary activities included rotating-credit schemes (Sindikiza), “Table-Banking," subsistence farming, brick-making, and early childhood education. Membership benefits, as perceived by most groups, included provision of extra income and "easy loans," acquisition of household items, and the establishment of nursery schools for young children.

\subsubsection{Selected Perceptions of Women Regarding Their Needs for Education and Training as it Pertained to the Acquisition of Vocational and Business Skills by Members of Their Self-Help Groups in the Shaviringa Location, Vihiga District of Western Kenya}

Most groups expressed the need for a trade school near their village so that all members could attend education and training sessions. "Hands-on" or facilitated instruction was the preferred mode of training. The groups preferred mainly agriculture and business training and the need for an adult literacy program was also highlighted. Additionally, most groups supported the establishment of a mobile training unit (MTU); one group favored a community training center.

\subsubsection{Selected Perceptions of Women Regarding Access to Information and Use of Communication Channels by Members of Their Self-Help Groups in the Shaviringa Location, Vihiga District of Western Kenya}

Word of mouth, local village meetings (i.e., Baraza in Swahili), attending funerals, and radio broadcasts were the primary sources of information for all the groups. The most reliable interpersonal communication networks were market centers, village 
shops, funeral ceremonies, church functions, village opinion leaders, cultural ceremonies, and village development committees. Some groups relied on written communication by designated members.

\subsubsection{Selected Perceptions of Women Concerning the Governance, Management, and Leadership of Their Self-Help Groups in the Shaviringa Location, Vihiga District of Western Kenya}

General governance, management, and leadership of the groups were influenced by registration status of the group, selection of group leaders, sources of conflicts, and from where a group operated. Most of the groups were registered with the government. In most groups, trust, education, and participation in group activities were members' rationales for selecting their leaders; other factors included integrity, influence, and experience.

Nine groups elected their leaders by a majority of votes cast, the other two groups "nominated" their leaders. Sources of conflicts within the groups were attributed to tardiness, using domestic issues as a rationale for tardiness, absenteeism, slow repayment of loans, leadership, and accountability issues.

\subsubsection{Selected Perceptions of Women Regarding the Financial Operations of Their Self-Help Groups in the Shaviringa Location, Vihiga District of Western Kenya}

Only three groups had opened bank accounts; the other eight groups lacked bank accounts due to insufficient capital as well as prohibitive bank fees. Most groups kept some form of records of their activities. 
All groups admitted to having minimal business experience but depended on group-raised capital to engage in business. Due to lack of capital, all the groups favored external assistance (e.g., seed capital) for expansion of their income-generating activities.

\subsubsection{Selected Perceptions of Women Regarding Other Factors That Affected the Performance of Their Self-Help Groups in the Shaviringa Location, Vihiga District of Western Kenya}

Other factors that affected the efficiency of the women's groups were marketing, transport of goods produced, and lack of motivations from or appreciation by their local communities. Poor prices or local demand, competition, and the inability to access large urban markets hindered the groups' marketing efforts.

The popular local means of transport included bicycles, taxi services, and, generally, walking to markets or functions. Long distance walking was an impediment to the groups' productivity due to advancing age and household duties of their members. It was perceived that transport agents capitalized on such inabilities to exploit women's groups thus affecting their profitability.

Eight groups perceived that culturally rooted gender bias was a major hinderance to their operations. The groups revealed that they lacked new ideas or skills to improve their existing activities because most members had minimal education. As a result, all the groups tended to duplicate projects carried out by others. As a remedy, most groups suggested that education and training through seminars and workshops be offered by government agencies and NGOs. Also, it was perceived that group-provided demonstrations and local shows stood a higher chance of contributing to the education and training of the groups' members. The women's self-help groups also expressed that 
their roles in community development needed to be appreciated through "appropriate rewards."

\subsubsection{RECOMMENDATIONS}

\subsubsection{Recommendations for Practice}

Based on the findings of this study, the following recommendations are offered for practice.

1. Most of the women's self-help groups operated without any set of rules (e.g., bylaws) to govern their operations, and, thus, conflicts were frequent. Working with a set of governing rules is something that could be introduced and communicated to the women's groups through education and training sessions. The Kenyan Government or an NGO with the necessary expertise could provide this assistance.

2. The larger the group, the more times it tended to meet. Because the potential for growth of the groups exists, it is possible that in the future they would become larger, which may affect the frequency of group meetings. So, it is recommended larger groups consider forming executive bodies that could meet more frequently and general meetings to include all members be scheduled regularly either monthly or twice a month. Also, larger groups could form sub-groups with special tasks or concerns to meet regularly and all their members could meet once a month.

3. Rotating-credit schemes (Sindikiza) and "Table Banking" were common financial operations carried out by the groups. A local or community-based cooperative and savings society could be established in collaboration with local Kenyan government authorities to help women better engage in savings programs and also improve their access to small loans. The need exists to provide grant writing assistance to the 
women's self-help groups for the purpose of soliciting funds to support the development of a savings cooperative. However, the education level of the group's members would need to be taken into account, i.e., their abilities to read and write, in particular.

4. Interest generated from "Table-Banking" loans could be used by groups to open bank accounts and initiate some savings for the groups' future income-generating activities. Such savings accounts could be opened with the Kenya Post Office Savings Bank, which are affordable and found in all areas of Kenya abundantly.

5. A majority of the women's self-help groups did not have proper meeting places and had to rotate group meetings and activities between their members' homes. So, it is recommended that the local community leaders, external actors such as NGOs, the Kenya government, and institutions of higher education pool resources to establish a community center in the Shaviringa Location. Such a center could assist women's self-help groups with planning and carrying out their activities as well as the coordination and delivery of training and education activities.

6. Most women's self-help groups were involved in entrepreneurial or incomegenerating activities that involved some form of business ventures. However, many of the groups were duplicating the projects of others. Feldman (1983) attributes the duplication of projects to the existing competition for a small limited market. Herz (1989) argues that it is due to a deficiency of skills in management and the general lack of viable markets for their income-generating activities that seems to characterize many women's groups. Therefore, it is recommended that the women's self-help groups be accorded training in the development of business plans and 
provided guidance about how best to avoid redundancy or undue duplication of projects and activities.

7. Government officials, who may be charged with facilitating the growth and functioning of women's self-help groups, should consider assisting the leaders of these groups in forming a "council" or location-wide board to include representatives of all groups. Through such a board, the problem of duplication of groups' efforts regarding income-generating activities could be reduced if not eliminated entirely.

8. Most of the women's self-help groups were founded to help Kenyan orphans access early childhood education opportunities. This is an extremely high need and important goal, and it is one that is congruent with the Kenyan Government's need to provide universal education for children (GOK, 2003) as envisioned by the Millennium Development Goals (United Nations, 2007). Both local and foreign institutions of higher education are needed to partner with rural communities in Kenya to help develop rural early childhood programs in rural areas. However, structured, targeted, and sustained assistance needs to be sought from appropriate Ministry(ies) of the Kenyan Government as well as select NGOs with the necessary expertise to better fulfill the need of providing early childhood education for the orphaned children of the Shaviringa Location.

9. The women's self-help groups were also involved in subsistence farming as well as limited food production for sale. So, the need exists for the Kenyan Government and other external actors to help develop and deliver basic and targeted agricultural educational programs that could address the needs of women in the area of food security and providing food for sale in the markets (Feldman, 1983). 
10. The providers of training and education, that is now being delivered to the women's groups interviewed or may be planned in the future, should consider the implementation of a mobile training unit (MTU). This approach to delivery would stand to improve the participation of women in such training and education programs (Shibanda \& Seru, 2002).

11. To help women's self-help groups address the problem of transporting their goods, a MTU could be fitted to assist (i.e., storage capacity) with moving women's self-help groups' products and services to and from the markets.

12. In order to better motivate women and highlight their role in community development through self-help groups, the implementation of a local 'Women's Self-Help Groups' Day" is recommended to "showcase" their activities and demonstrate a communal and official spirit of appreciation for group members' interest in and efforts to improve their community.

13. An executive summary of this study should be developed and then shared with the appropriate Government of Kenya Ministry(ies) as well as NGOs or similar aid groups that operate in the Shaviringa Location whose interests may intersect with the purposes and needs of the women's self-help groups interviewed.

14. Because many of the members of the women's groups interviewed are either elderly or approaching old age, it is possible they have acquired and accumulated special knowledge about indigenous farming systems, special skills, and the daily activities in their area (Dudwick et al., 2003; Mutua-Kombo, 2001; Steeves, 1996). This knowledge may be in jeopardy of being lost due to their eventual deaths. Therefore, it is recommended that all groups devise strategies to recruit younger women who could 
be taught those skills so that they can help preserve such indigenous or "special" knowledge. Also, it is recommended that future projects document and archive this knowledge using contemporary technology such as film or digitized video. This could, in turn, be shared with the entire community or used for general educational or promotional purposes in the public and private sectors.

15. The findings of this study could be used to provide the narrative for a video documentary with which to recruit potential group members, publicize groups' activities, or archive the roles of women's self-help groups in the Shaviringa Location. Accordingly, these findings could be more readily shared with the people of Shavringa Location.

16. Based on the finding that some local or national NGOs gave projects such as beehives to women without educating and training them first or concurrently, it is recommended that the real needs of local groups be "authenticated" or established before assistance is offered or implemented. This, in turn, could help reduce some of the "top-down" practices by NGOs in the region and help them to devise strategies to better communicate with rural citizens.

17. Radio and television broadcasts are common mass media communication channels in Kenya. So, it is recommended that special rural development programs focused on the activities of women's self-help groups be incorporated into mainstream broadcast programming (Mutua-Kombo, 2001; Steeves, 1996). This could raise awareness of the roles of women's self-help groups in community development. Specific Government of Kenya Ministry(ies), local or foreign aid agencies, educational 
institutions, and commercial agencies could be sources of resources and expertise for such programs.

\subsubsection{Recommendations for Future Research}

Based on the findings of this study, the following recommendations are offered for future research.

1. Due to younger women failing to join women's self-help groups in proportion to older women, the need exists to identify the reasons that may be impeding their participation in self-help groups. A study should be carried out to examine the rationale for non-participation held by women under 40 years of age.

2. Additional research is also recommended to better understand the issues surrounding the possibility of having training that would include both genders and mixed ages, i.e., men and youth, alongside women in future training and education programs. For example, do culturally rooted norms and taboos need to be addressed or mitigated before implementing such a model?

3. To help women's self-help groups overcome marketing problems, more research is needed to determine the type of projects in which they could engage that would be in demand locally as well as in larger urban markets, especially those that are likely to yield a reliable return on their investments (i.e., carry out a market analysis), as postulated by Buvinic (1997) and Feldman (1983).

4. More research is needed to provide solutions to the problem of transportation that affects the movement and sale of goods and services by women's self-help groups in the Shaviringa Location. 
5. To prevent the loss of skills and special knowledge, future studies need be undertaken to document the "special knowledge and skills" possessed by older members of women's self-help groups in the Shaviringa Location.

6. There need exists for an investigation to examine how best to incorporate the activities of women's self-help groups into appropriate curriculum in educational institutions in Kenya to increase education and awareness about their origin, purpose, roles, and significant socio-cultural functions.

\subsubsection{DISCUSSION AND IMPLICATIONS}

Young women had a tendency to be excluded from the women's groups interviewed; the groups predominantly attracted older women. Even though there are many young women (less than 40 years of age in the Shaviringa Location of Western Kenya), they may be unlikely to join a group that is dominated by older women.

There was a strong perception that raising dairy cattle demanded much attention and were too vulnerable to attack by tick-borne diseases despite a high demand for milk and desire by groups to pursue such projects. Another challenge was acquisition of feedstuffs for both cattle and poultry because commercially produced animal feeds were expensive. However, locally produced feedstuffs were not easy to accumulate because women lived on separate farmsteads, which are relatively small (Waithaka et al., 2006).

Similar arguments were expressed by the only group that had a bee-keeping project. The women stated that they did not receive much training on bee-keeping and were always exploited by middle-men and NGOs who supplied them with the beehives. African bees are dangerous and so women had to hire people (without training) to set up the hives, maintain the site, and harvest the honey. Because of the fear of bees and lack of 
proper protective equipment, they were always late in harvesting honey. The women explained that most of the men hired would steal the honey. (The local market for honey was primarily for medicinal purposes, whereas, urban centers use honey in the hospitality industry). This may imply that some NGOs are taking advantage of vulnerable groups which they are supposed to help. Lack of training and follow-up programs for women's self-help groups is a crucial to the success of groups (Feldman, 1983; Noordin, Niang, Jama, \& Nyasimi, 2001).

High population and the shortage of land required that some groups rent land for cultivation and use female casual labor. This supports the argument that Vihiga District is highly populated and pressures on land resources are immense resulting in overuse and reliance on subsistence farming (Waithaka et al., 2006). An additional cause could be a result of the fact that land ownership is still a preserve of men (Srujana, 1996). Proceeds from the sale of products were subdivided among the members and used on other projects such as construction of houses or acquisition of dairy cattle. But due to lack of appropriate advice, women's self-help groups sometimes engaged in the cultivation of crops that lacked local market appeal (e.g., bananas) but were in demand in urban centers; however, transport may then be an issue. This may mean that women's self-help groups have the potential to engage in dairy production if they receive some assistance.

Similar arguments were expressed by the only group that had a bee-keeping project. Such projects have the potential of improving the lives of women in the community but without proper education and training they are regarded as a loss and a waste of resources. This is also an example of how women's self-help groups may fall prey to unscrupulous non-governmental organizations. It also points to the need of 
educating women's self-help groups before giving them certain types of projects or resources. Herz (1989) and Kane et al., (1991) pointed out the need for strengthening the management and logistical capabilities of women's groups. On the other hand, the study by Stevenson and St-Onge (2005) on women involved in entrepreneurship revealed that most training did not account for rural areas, was devoid of follow-up, and placed little emphasis on aspects such as business and marketing. Those and related issues must be addressed if successful sustainable development is the objective.

Because almost all the self-help groups were formed to help widows and orphans, the problem of orphans is major challenge in the Shaviringa Location, Vihiga District of Western Kenya. So, future intervention measures need to be devised to complement the efforts by women's self-help groups. Waters and Haskell (1988) affirmed that needs assessments were vital to the design and implementation of programs for education and training that would be based on the expressed perceptions of clients.

Information is power. But in rural areas citizens need key information that can enable them to break the cycle of poverty and other cultural barriers preventing marginalized groups such as women and youth to improve their standards of living (Mutua-Kombo, 2001). Steeves (1996) argued that improving the lives of women was tangential to access to education and information, which could result in smaller families, long life expectancies and better health and nutrition. Women's self-help groups have special knowledge about their needs in areas such as agriculture and what can be done to help mitigate those needs (Steeves, 1996).

Moreover, rural areas are frequently confounded by strong cultural practices and attitudes that impede on their development; such attitudes may be eradicated through the 
dissemination of information that uses existing interpersonal communication networks which are considered socially acceptable (Rogers, 2003).

Mass media may offer opportunities for improved information access as well. For example, most of the billboard advertisements in the rural or urban centers in Kenya are replete with advertisements by commercial enterprises, or on health, AIDS, and political messages. However, it is important to realize that the effects of poverty outweigh those of HIV-AIDS, i.e., it "trumps" or is associated with the other ills that face a society. Therefore, the need exists to dedicate more resources to eradicating poverty, especially in the rural areas, using all possible avenues of communication and information dissemination such as billboards (GOK, 2003). The same applies to radio and television programs and broadcasts. Managers of media outlets (print and electronic) should be sensitized about the need to provide information that specifically addresses the activities and challenges of women's self-help groups in rural areas (Mutua-Kombo, 2001).

Because a tax is levied on the registration of associations, including women's self-help groups, the Government of Kenya should use collected monies to start a local or regional fund to support women's self-help groups. Such a fund would be disbursed as small loans that could serve as "seed capital" for the self-help groups. Such a system could be developed as a cooperative savings society. This approach might prompt more women to join self-help groups and, perhaps, generate more revenue that could be, in turn, used to assist more women in rural areas of Kenya. This kind of initiative might reduce the challenges that many women's groups face when trying to access loans from banking institutions. 
The financial operations of women's self-help groups are critical in their quest to mitigate poverty and overcome other social and welfare challenges. Even though most groups in this study were multipurpose, an underlying factor was that they were all involved in some form of income-generating activity. When examining the impact of women's self-help groups, one pertinent question is whether these associations present viable solutions or alternatives to the problems of poverty and unemployment women face (Srujana, 1996). As Stevenson and St-Onge (2005) pointed out, entrepreneurial, management, and technical training are crucial to enterprise development.

Because Western Kenya is a culturally rich region, the need exists to examine the existing cultural practices with a view of making them more gender-balanced. This could be achieved through local education and training activities and by employing local interpersonal communication networks and opinion leaders (Rogers, 2003). For example, cultural practices that forbid women, even though they are more involved in production of food, from planting trees may be depriving the local community of significant conservation efforts and impacting the fertility of its soils and the availability of water. The activities of women's self-help groups could have greater economic impact if existing cultural bias regarding the division of labor between men and women changed (Herz, 1989; Noordin et al, 2001; Steeves, 1996). This would involve focusing on areas where the needs of women are greatest and the means to satisfy them are absent.

Judging from activities described by the groups interviewed, it was possible that their members could serve in jobs that are considered "masculine," such as construction (e.g., one group's reference to brick-making). With proper education and training in accounting and related business practices, the performance of the associations might be 
improved as well. Shibanda and Seru (2002) recommended education and training programs that are close to where women's groups operate, paying attention to the daily schedules of women; this could in turn serve as a motivation or incentive for them to attend rural education and training initiatives. Devising ways and means of appreciating the roles of women's self-help groups may go a long way in motivating them as well as inspiring others (e.g., younger women) to join and bring new ideas to the groups. Such an initiative, as the women interviewed asserted, could be facilitated by local nongovernmental agencies and the Government Kenya, which is committed to promoting such community-based initiatives (GOK, 2003). This supports the arguments by Shibanda and Seru (2002) that education and training sessions to equip women's selfhelp groups can be facilitated by a combination of development agencies.

Vocational training schools, known in Kenya as "village youth polytechnics," serve rural populations by delivering vocational skills that enable youth to gain "selfemployment" which is congruent with one of Kenya's development objectives, i.e., "freedom from want, ignorance and exploitation; equal opportunity for all; a high per capita income equally distributed; and economic self-reliance" (Srujana, 1996, p. 33). Moreover, due to population increases in Kenya in the past several decades, the demand for education has risen, yet the government of Kenya has not fully met that need (GOK, 2003). The rural areas are most affected by limited training opportunities; this has been an impetus for the rural-urban migration, especially by males. So, ultimately, rural areas are left with the elderly, women, and children; most important, rural areas are denied of a potential workforce that could have been used to further their development (Kiteme, 1992). Therefore, the construction of a local trade school could potentially halt or reduce 
rural Kenyans who migrate to urban centers in search of training and education. Because most vocational and training centers are located in urban centers, such an initiative could generate employment opportunities that are needed for poverty alleviation in the rural areas (House, 1984; Neitzert, 1996; Ziderman, 2003).

What is more, in the absence of such training and educational opportunities in the rural areas, very little prevents males from migrating in search of better economic opportunities. For those youth who remain behind, many of them commit petty crimes that causes insecurity in rural areas. These problems are sometimes more pronounced for girls, who without proper education, become child laborers (e.g., house maids) in urban centers. They work for meager wages that go toward supporting their families in rural areas or they enter into in early marriages and start raising families without a firm economic foundation. Frequently, they then resort to casual labor services in order to afford the basics of life; ultimately, they complete the cycle of poverty, i.e., the "feminization of poverty" (Buvinic, 1997) continues. As Nichols-Casebolt, Krysik, and Hermann-Currie, (1994) posited, women and girls have a greater potential of being exploited by some of the prevailing social and economic constraints that perpetuate a cycle of low-education and low-paying jobs from one generation of women another. Even though there are interventions at the household level, they seem to be insufficient, so, there is need to diversify the socio-economic opportunities (Bardan, 1996).

So, if trade schools were constructed, per the wishes of the members of the selfhelp groups interviewed, most youth could take advantage of such opportunities to learn new skills that may diversify their sources of income. Even though such training is intended for women, the same opportunity could be extended to men. As one group 
stated, "men have the ability to understand certain vocations faster and better." If both men and women acquire such skills, it could confer more financial security to many rural households 


\section{REFERENCES}

Anderson, D., \& Leiserson, M. W. (1980). Rural nonfarm employment in developing countries. Economic Development and Cultural Change, 28(2), 227-248.

Ashley, C., \& Maxwell, S. (2001). Rethinking rural development. Development Policy Review, 19(4), 395-425.

Bandura, A. (1995). Exercise of personal and collective efficacy in changing societies. In A. Bandura (Ed.), Self-efficacy in changing societies (pp. 1-45). Cambridge: Cambridge University Press.

Bardhan, P. (1996). Efficiency, equity and poverty alleviation: Policy issues in less developed countries. The Economic Journal, 106(438), 1344-1356.

Bent-Goodley, T. B. (2002). Defining and conceptualizing social work entrepreneurship. Journal of Social Work Education, 38(2), 291-302.

Besley, T., \& Burgess, R. (2003). Halving global poverty. The Journal of Economic Perspectives, 17(3), 3-22.

Business: Central Bank of Kenya (CBK) rates. The Daily Nation. Retrieved 11/29/2007, from http://nationmedia.com/dailynation/nmgbusiness.asp?categoryid=3

Buvinic, M. (1997). Women in poverty: A new global underclass. Foreign Policy, 108, $38-53$.

Cagatay, N. (1998). Gender and poverty (No. 5). New York: United Nations Development Program. 
Chant, S. (2006). Re-thinking the "Feminization of Poverty" in relation to aggregate gender indices. Journal of Human Development, 7(2), 201-220.

Chossudovsky, M. (1998). Global poverty in the late $20^{\text {th }}$ century. Journal of International Affairs, 52(1), 293-311.

Christiaensen, L., Lionel, D., \& Paternostro, S. (2003). Macro and micro perspectives of growth and poverty in Africa. The World Bank Economic Review, 17(3), 317-347.

Clark, M. H. (1984). Woman-headed households and poverty: Insights from Kenya. Signs, 10(2), 338-354.

Collier, P., \& Gunning, J. W. (1999). Why has Africa grown slowly? The Journal of Economic Perspectives, 13(3), 3-22.

Creswell, J. W. (2005). Educational research: Planning, conducting, and evaluating quantitative and qualitative research (2nd ed.). Upper Saddle River, NJ: Pearson Merrill Prentice Hall.

Daniels, L., \& Mead, D. C. (1998). The contribution of small enterprises to household and national income in Kenya. Economic Development and Cultural Change, $47(1), 45-71$.

Dudwick, N., Gomart, E., Marc, A., \& Kuehnast, K. (2003). When things fall apart: Qualitative studies of poverty in the former Soviet Union. Washington, D.C: The World Bank.

Ettema, W. (1984). Small-scale industry in Malawi. Journal of Modern African Studies, 22(3), 487-510. 
Feldman, R. (1983). Women's groups and women's subordination: An analysis of policies towards rural women in Kenya. Review of African Political Economy, 10(27/28), 67-85.

Fossey, E., Harvey, C., McDermott, F., \& Davidson, L. (2002). Understanding and evaluating qualitative research. Australian and New Zealand Journal of Psychiatry, 36(6), 717-732.

Freeman, H. A., Ellis, F., \& Allison, E. (2004). Livelihoods and rural poverty reduction in Kenya. Development Policy Review, 22(2), 147-171.

Fukuda-Parr, S. (1999). What does feminization of poverty mean? It isn't just lack of income. Feminist Economics, 5(2), 99-103.

Global Poverty Report. (July, 2000). Paper presented at the G8 Global Poverty Summit, Okinawa, Japan.

Government of Kenya (GOK):1999 population and housing census. Counting our people for development. (2001). Central Bureau of Statistics, Ministry of Finance and Planning, Nairobi, Kenya.

Government of Kenya: Economic recovery strategy for wealth and employment creation 2003-2007. (2003). Ministry of Planning and National Development. Nairobi: Government Printer.

Greenberg, I. (2007). Vocational education, work culture, and the children of immigrants in 1930s Bridgeport. Journal of Social History, 41(1), 149-160. 
Helmore, K., \& Singh, N. (2001). Sustainable livelihoods: Building on the wealth of the poor. Bloomfield, CT: Kumarian Press.

Herz, B. (1989). Women in development: Kenya's experience. Finance and Development, 26(2), 43-45.

House, W. (1984). Nairobi's informal sector: Dynamic entrepreneurs or surplus labor? Economic Development and Cultural Change, 32(2), 277-302.

Hulme, D., \& Shepherd, A. (2003). Conceptualizing chronic poverty. World Development, 31(3), 403-423.

Kamalkhani, S. K. (1991). Promoting local capital: The role of small enterprise development corporation (SEDCO) in Swaziland. Journal of Southern African Studies, 17(2), 191-196.

Kamar, J. M. (1999). Role of Kenyan women's groups in community based soil and water conservation: A case study. Retrieved August 22, 2007, from http://topsoil.nserl.purdue.edu/fpadmin/isco99/pdf/ISCOdisc/SustainingTheGloba 1Farm/P219-Kamar.pdf

Kane, K., Walsh, M., \& Nelson, C. (1991). A case for business training with women's groups. Small Enterprise Development, 2(1), 13-19.

Karani, F. (1987). The situation and roles of women in Kenya: An overview. The Journal of Negro Education, 56(3), 422-434.

Karega, R. G. M. (1996). Women's groups: From welfare to small-scale business in Kenya. Small Enterprise Development, 7(1), 31-41. 
Kempe, R. H. (2004). The poverty dilemma in Africa: Toward policies for including the poor. Progress in Development Studies, 4(2), 127-141.

Kiteme, K. (1992). The socioeconomic impact of the African market women trade in rural Kenya. Journal of Black Studies, 23(1), 135-151.

Kristjanson, P., Krishna, A., Radeny, M., \& Nindo, W. (2004). Pathways out of poverty in Western Kenya and the role of livestock. Working paper for the FAO/Pro-poor livestock policy initiative (No. 14): International Livestock Research Institute.

Krueger, R. A. (1999). Focus Groups: A practical guide for applied research (2nd ed.). Thousand Oaks, CA: SAGE Publications, Inc.

Krueger, R. A. (2000). Focus Groups: A practical guide for applied research (3rd ed.). Thousand Oaks, CA: SAGE Publications, Inc.

Lanier, A. R. (1968). Women in the rural areas. Annals of the American Academy of Political and Social Science, 375, 115-123.

Liedholm, C., McPherson, M., \& Chuta, E. (1994). Small enterprise employment growth in rural Africa. American Journal of Agricultural Economics, 76(5), 1177-1182.

Livingstone, I. (1977). An evaluation of Kenya's rural industrial development programme. The Journal of Modern African Studies, 15(3), 495-504.

MacKenzie, F. (1986). Local initiatives and national policy: Gender and agricultural change in Murang'a District, Kenya. Canadian Journal of African Studies, 20(3), $377-401$. 
Marcoux, A. (1998). The feminization of poverty: Claims, facts, and data needs. Population and Development Review, 24(1), 131-139.

Mayoux, L. (1999). Questioning virtuous spirals: Microfinance and women's empowerment in Africa. Journal of International Development, 11, 957-984.

Mbugua-Murithi, T. (1997). Strategies for survival in Kenya: Women, education, and self-help groups. International Journal of Educational Reform, 6(4), 420-427.

Merriam, S. B. (1998). Qualitative research and case study applications in education. San Francisco: Jossey-Bass Publishers.

Morduch, J. (1999). The Micro-finance promise. Journal of Economic Literature, 37(4), 1569-1614.

Morgan, D. L. (1997). Focus groups as qualitative research (2nd ed.). Thousand Oaks, CA: Sage Publications.

Mutua-Kombo, E. (2001). Women's groups and information provision in rural Kenya. Library Review, 50(4), 193-196.

Mwabu, G., \& Thorbecke, E. (2004). Rural development, growth and poverty in Africa. Journal of African Economies, 13(1), 16- 65.

Mwaniki, N. (1986). Against many odds: The dilemmas of women's self help-groups in Mbeere, Kenya. Africa: Journal of the International African Institute, 56(2), 210228. 
Neitzert, M. (1996). Human capital in the hot sun. Economic Development and Cultural Change, 45(1), 69-87.

Nichols-Casebolt, A., Krysik, J., \& Hermann-Currie, R. (1994). The povertization of women: A global phenomenon. Affilia, 9(1), 9-29.

Noordin, Q., Niang., Jama, B., \& Nyasimi, M. (2001). Scaling up adoption and impact of agroforestry technologies: Experiences from Western Kenya. Development in Practice, 11(4), 509-523.

Northrop, E. M. (1990). The feminization of poverty: The demographic factor and the composition of economic growth. Journal of Economic Issues, 24(1), 145- 160.

Oettingen, G. (1995). Cross-cultural perspectives on self-efficacy. In A. Bandura (Ed.), Self-efficacy in changing societies (pp. 149-176). Cambridge: Cambridge University Press.

Oketch, M. O. (2007). To vocationalise or not to vocationalise? Perspectives on current trends and issues in technical and vocational education and training (TVET) in Africa. International Journal of Educational Development, 27(2), 220-234.

Okonjo, K. (1979). Rural women's credit systems: A Nigerian example. Studies in Family Planning, 10(11/12), 326-331.

Patton, M. Q. (1990). Qualitative evaluation and research methods (2nd ed.). Newbury Park, California: SAGE Publications, Inc.

Pearce, D. (1992). The feminization of poverty: Women, work, and welfare. Urban and Social Change Review, 11(1-2), 28-36. 
Perry, D. (2002). Micro-credit and women money lenders: The shifting terrain of credit in rural Senegal. Human Organization, 61(1), 30-40.

Rogers, E. M. (2003). Diffusion of innovations (5th ed.). New York: Free Press.

Seidman, A. (1977). Problems of industrialization in Africa. A Journal of Opinion, 7(4), 23-25.

Shibanda, G. G., \& Seru, J. I. (2002). Human resource strategy for Kenyan women smallholders. Women in Management Review, 17(6), 285-296.

Snow, D. R., \& Buss, T. F. (2001). Development and the role of microcredit. Policy Studies Journal, 29(2), 296-307.

Sperling, G., \& Hart, T. (2003). A better way to fight global poverty: Broadening the Millennium Challenge Account. Foreign Affairs, 82, 9-14.

Srujana, K. (1996). Status of women in Kenya: A sociological study. Delhi: Kalinga Publications.

Steel, W. F., \& Takagi, Y. (1983). Small enterprise development and the employmentoutput trade-off. Oxford Economic Papers, 35(3), 423-446.

Steeves, H. L. (1996). Sharing information in Kenya: Communication and information policy considerations and consequences for rural women. International Communication Gazette, 56(3), 157-181.

Stevenson, L. \& St-Onge, A. (2005). Support for growth-oriented women enterprises in Kenya. Geneva: International Labor Organization. 
The Daily Nation. Many Kenyans borrow money from their neighbors. Retrieved 11/20/2007, from http://nationmedia.com/dailynation

Theodori, G. L. (2005). Community and community development in resource-based areas: Operational definitions rooted in an interactional perspective. Society \& Natural Resources, 18(7), 661-669.

Thomas, B. P. (1987). Development through Harambee: Who wins and who loses? Rural self-help projects in Kenya. World Development, 15(4), 463-481.

Thomas, B. (1988). Household strategies for adaptation and change: Participation in Kenyan rural women's associations. Africa: Journal of the International African Institute, 58(4), 401-422.

Udvardy, M. L. (1998). Theorizing past and present women's organizations in Kenya. World Development, 26(9), 1749-1761.

United Nations. (2001). Road map towards the implementation of the United Nations Millennium Declaration. Report of the Secretary-General. Retrieved May 20, 2007, from http://www.un.org/documents/ga/docs/56/a56326.pdf

United Nations. (2007). Millennium Development Goals. Retrieved November 20, 2007, from http://www.un.org/millenniumgoals

Waithaka, M. M., Thornton, P. K, Herrero, M., \& Shepherd, K. D. (2006). Bio-economic evaluation of farmers' perceptions of viable farms in western Kenya. Agricultural Systems, 90(1-3), 243-271. 
Waters, R. G., \& Haskell, L. J. (1989). Identifying staff development needs of cooperative extension faculty using a modified Borich needs assessment model. Journal of Agricultural Education, 30(2), 26-32.

Weatherby, J. N., Evans, E. B., Gooden, R., Long, D., \& Reed, I. (2003). The other world: Issues and politics of the developing world (5th ed.). New York: Longman Publishing Group.

White, H. (1999). Global poverty reduction: Are we heading in the right direction? Journal of International Development, 11(4), 503-519.

Whitehead, A., \& Lockwood, M. (1999). Gendering poverty: A review of six World Bank African poverty assessments. Development and Change, 30(3), 525-555.

Ziderman, A. (2003). Financing vocational training in Sub-Saharan Africa. Washington, D.C: The World Bank. 
APPENDICES 
APPENDIX A 
IRB APPROVAL LETTER 


\title{
Oklahoma State University Institutional Review Board
}

\author{
Date: Tuesday, March 20, 2007 \\ IRB Application GU075 \\ Proposal Title: $\quad$ Improving the Livelinoods of Women in the Developing Warld: Selected \\ Perceptions From Vomen Self-Help Groups in Western Kenya \\ Reviewed and Expedited \\ Processed as:
}

Status Recommended by Reviewer(s):

Principal

Investigator(s):

Billy A. Jivetti Michael Craig Edwards

38 S. Univ. Place \#10 $448 \mathrm{Ag}$ Hall

Stillwater, OK $74075 \quad$ Stillwater, OK 74078

The IRB application referenced above has been approved. It is the judgment of the reviewers that the rights and welfare of individuals who may be asked to perticipate in this study wifl be respected, and that the research will be conducted in a manner consistent with the IRB requirements as outlined in section 45 CFR 46.

X The final versions of any printed recruitment, consent and assent documerits bearing the IRB approval atamp are atteched to this letter. These are the versions that must be used during the study.

As Principel Inveetigater, it is your responsibility to do the following:

1. Conduct this study exactly as it has been apprcved. Any modifications to the research protocol must be submitted with the appropriate signatures for IRB approval.

2. Submit a request for continuation if the study extends beyond the apprcval period of one calendar year. This contiruation must receive IRE review and approval betore the research can continue.

3. Report any adverse events to the IRB Chesir promptly. Adverse events are those which are unanticipated and impect the aubjects during the course of this research; and

4. Notify the IRB office in writing when your research project is complete.

Please note that approwed protocols are subject to monitoring by the IRB and that the IRB office has the authority to inspect research records associated with this protocol at any time. If you have questions abcut the IRB procedures or need any assistance from the Board, please contact Beth McTernan in 219 Cordel North (phone: 405-744-5700, beth.mcternan gekstate.edu).

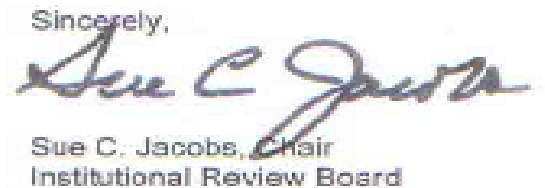


APPENDIX B 


\section{QUESTIONNAIRE}




\section{FOR THE INTERVIEWER}

Research Assistant

Date of Interview

Start Time

Stop Time

Venue

Name of the Women's Group

When did this group begin?

Number of members

\section{ANSWER THIS SECTION AFTER COMPLETING THE INTERVIEW}

Give an overall description of this women group

Number of Respondents

Language used $\square$ English $\square$ Swahili $\square$ Vernacular $\square$ Mixed

Challenges in getting information from this group 


\section{SURVEY QUESTIONS}

1. What is the age bracket of this group's members?

$\square$ 20-30 $\square$ 30-40 $\square$ 40-50 $\square 50-60 \square 60-70 \square 70-80$

2. What are the group's income generating activities?

○

$\bullet$

3. What are some of the benefits received through group membership?

a.

b.

4. Average amount of time spent on group activities

$\square$ Some hours $\square$ Daily $\square$ Once a Week $\square$ Once a month $\square$ Other

5. Is there a need for a trade school for training purposes?

$\square$ Yes $\square$ No

Reason(s) for having or not having a trade school

6. If a trade school was to be constructed, where would it be located?

$\square$ Village $\square$ Shopping Center $\square$ Town $\square$ Other

7. Who should attend training?

$\square$ All members $\square$ Chair Person $\square$ Treasurer $\square$ Secretary $\square$ None $\square$ Other

8. What are the preferred areas of training in the trade school?

$\square$ Family Planning $\square$ Agriculture $\square$ HIV-AIDS $\square$ Health \& Nutrition $\square$ Politics $\square$

Religion $\square$ Business $\square$ Entrepreneurship $\square$ Banking $\square$ Cultural $\square$ Other

9. Who would you prefer to train you?

$\square$ Trained Group Representatives $\square$ Government Official $\square$ NGOs $\square$ Trade \& Industry Representative $\square$ Educational Representative $\square$ Other

10. What is the preferred mode of training?

$\square$ Participatory $\square$ Discussion groups $\square$ Hands on training $\square$ Speaker/Lecture $\square$ Other

11. Is there a preference for a MOBILE TRAINING UNIT?

$\square$ Yes $\square$ No 
Reason(s) for having or not having a mobile training unit

12. What is/are your source of information?

$\square$ Word of Mouth $\square$ Radio $\square$ Television $\square$ Newspapers $\square$ Local Community

Meetings - Baraza $\square$ Other

13. What is the common interpersonal communication networks preferred?

Market centers $\square$ Village shops $\square$ Cultural ceremonies $\square$ Funeral $\square$ Community opinion leaders $\square$ Village committees $\square$ Other

14. What type of information do you prefer to receive?

$\square$ Business $\square$ Agriculture $\square$ HIV-AIDS $\square$ Religious $\square$ Politics $\square$ Cultural $\square$

Vocational Training $\square$ Trade $\square$ Other

15. How is information spread within the groups and others in the area?

$\square$ Dance and song $\square$ Messenger $\square$ Village committees $\square$ In-group communication

$\square$ Networks with NGOs $\square$ Other

16. Is the group officially registered with the government?

$\square$ Yes $\square$ No

If yes/not explain

17. How are group leaders selected?

$\square$ Elected $\square$ Appointed $\square$ Nominated $\square$ Volunteer $\square$ Other

18. What is the criterion (qualities) used to select a group leader?

$\square$ Trust $\square$ Popularity $\square$ Education $\square$ Active Participation $\square$ Ability to influence others $\square$ Other

19. Where does the group operate from?

$\square$ Home $\square$ Church $\square$ School $\square$ Built Premises $\square$ Rent space $\square$ Community Center

$\square$ Other

20. What Factors limit this group's equal participation in community development?

$\square$ Culture $\square$ Education $\square$ Lack of capacity building $\square$ Gender bias $\square$ Capital

$\square$ Other

21. Does the group have a Bank Account?

$\square$ Yes $\square$ No 
Reason(s) for having or not having an account

22. If No, where is the money kept?

$\square$ House $\square$ Individual Members $\square$ Leaders $\square$ Other

23. Who manages the bank account?

$\square$ Chair $\square$ Treasurer $\square$ Don't know $\square$ Secretary $\square$ Other

24. Does the group keep records?

$\square$ Yes $\square$ No

Reason(s) for keeping or not keeping records

25. If Yes, what type of records are kept?

26. Is there a demand for the group's goods and services?

$\square$ Yes $\square$ No $\square$ Other

27. Is the group's income generating activities different from that/those of other groups?

$\square$ Yes $\square$ No

28. How does transportation affect the group's activities?

29. What are the major sources of conflicts in the group?

$\square$ Leadership Issues $\square$ Transparency \& Accountability $\square$ Domestic feuds $\square$ Local politics $\square$ Government interference $\square$ Sharing costs of production $\square$ Unequal labor division

$\square$ Unfair distribution of profits $\square$ Other

Additional Explanation 
30. What is the highest Education Level?

$\square$ None $\square$ Some Primary $\square$ Primary $\square$ High school $\square$ Vocational $\square$ College $\square$ University

31. Does the group [members] have any business experience?

Yes $\square$ No

32. How many group members have business experience?

$\square$ None $\square$ All $\square$ Other

33. Give the number of years of business experience.

$\square$ None $\square$ Some $\square 1$ year $\square$ Over Five $\square$ Other

34. If a small seed-grant/capital were available, how much would be helpful?

1 3 4

35. What would be the top-priority for using a start-up/seed capital/grant?

$\square$ Building $\square$ Material $\square$ Equipment $\square$ Training $\square$ Other

36. What constrains the group's efforts in [business] expansion?

$\square$ Time $\square$ Market $\square$ Raw Materials $\square$ Capital $\square$ Training $\square$ Other

37. What are some of the barriers to marketing your products?

Transportation $\square$ Poor local market demand $\square$ Poor Market prices $\square$ Competition Lack of access to larger market (in town/urban centers) $\square$ Other

38. What is your motivation for undertaking [income-generating activities]?

$\square$ Training $\square$ Education $\square$ Determination to end poverty $\square$ Advice from Extension Staff $\square$ Follow-up and advice from Local Leaders $\square$ Good group Leadership $\square$ Expected Benefits $\square$ Government Support $\square$ Other

39. What contributes to the success of women group's activities?

Advice and Visits by extension staff $\square$ Full participation \& cooperation among members $\square$ Material/tool Support by the government $\square$ Self motivation $\square$ Good leadership $\square$ Seminars/training at the start $\square$ Support from husbands $\square$ Other

40. What are the MAIN setbacks encountered by the group?

$\square$ Inadequate funds $\square$ Poverty among members $\square$ Lack of new Ideas $\square$ Completion of already existing projects $\square$ Multiple roles (conflict between group \& individual commitments) $\square$ Inactive members $\square$ Other

41. What are your suggestions for improving women groups?

Education Training $\square$ Government provision $\square$ Advice and follow-up by extension officers $\square$ Involving local administration $\square$ Motivation through tours, shows, awards, 
demonstration $\square$ Periodic $\square$ Evaluation $\square$ Good Leadership $\square$ Training in Leadership and Management Skills $\square$ Other

42. How can women be motivated to increase group participation?

$\square$ Competitions with other groups $\square$ Tours $\square$ Appropriate Rewards

Demonstrations $\square$ Education and Training $\square$ Other

43. How should the education and training be conducted?

$\square$ Seminars \& Workshops $\square$ At a Trade School $\square$ Mobile Training Unit $\square$ Mass Media [Radio, TV] $\square$ Demonstrations $\square$ Other

\section{THE END}


VITA

Billystrom Aronya Jivetti

Candidate for the Degree of

Master of Science

Thesis: IMPROVING THE LIVELIHOODS OF WOMEN IN THE DEVELOPING WORLD: SELECTED PERCEPTIONS OF WOMEN'S SELF-HELP GROUPS IN WESTERN KENYA

Major Field: International Studies

Biographical:

Personal Data:

Education:

Completed the requirements for the Master of Science in International Studies at Oklahoma State University, Stillwater, Oklahoma in December, 2007.

Experience:

Professional Memberships: 
Title of Study: IMPROVING THE LIVELIHOODS OF WOMEN IN THE DEVELOPING WORLD: SELECTED PERCEPTIONS OF WOMEN'S SELF-HELP GROUPS IN WESTERN KENYA

Pages in Study: 122

Candidate for the Degree of Master of Science

Major Field: International Studies

Abstract

Development specialists agree that poverty in developing countries is a multidimensional phenomenon. The United Nations reported that the poorest of the world's poor are women. The Kenyan Government recognizes that poverty is area specific and interventions aimed at creating employment and reducing poverty must be localized. In Kenya, "women's self-help groups" have become popular avenues through which women in rural areas complement efforts toward alleviating poverty. This study examined women's groups (Sindikiza Maisha) in Western Kenya regarding members' perceptions on improving their livelihoods. Semi-structured, focus group interviews were used to collect data from 11 groups. Most groups were formed to assist HIV-AIDS-related orphans or widows. Groups expressed the need for a local trade school and supported the establishment of a mobile training unit (MTU). Policy-makers who are charged with alleviating poverty should consider the implementation of a MTU and the construction of a trade school in the Shaviringa Location.

Keywords: Kenya, Women's Groups, Training, Education, Mobile Training Unit 